\title{
Fieldwork in southern Viti Levu and Beqa Island
}

\author{
Atholl Anderson \\ Archaeology and Natural History, The Australian National University \\ Geoffrey Clark \\ Archaeology and Natural History, The Australian National University
}

\section{Introduction}

This chapter is concerned with research in southern Viti Levu and on Beqa Island, which lies off the south coast of Viti Levu. The investigations can be divided into four parts, based on site geography (Figure 35). Much of the early fieldwork effort concentrated on the lower and middle Sigatoka Valley and nearby areas of the south coast of Viti Levu. The Sigatoka, at $137 \mathrm{~km}$ long, is the second largest river in Fiji, after the Rewa. Its lower and middle reaches run through the relatively dry leeward zone of Viti Levu and annual rainfall in the valley is around $2000 \mathrm{~mm}$. Originally forested, the Sigatoka Valley is noted for its soil fertility and had become intensively cultivated and densely populated by the 19th century; Parry (1987:53) estimates a protohistorical population of 18,000-22,000. His aerial-photo survey of archaeological sites counted 212 settlements, the majority, not unexpectedly, exhibiting earthworks. The fortification tradition, according to Parry (1987:119), was particularly well developed in the Sigatoka and has origins which can be traced as far back as the second millennium AD (Field 2004). If the significance of the Sigatoka through the last millennium suggests it was regarded as attractive for settlement, then perhaps this was so from the earliest period of human habitation in Fiji. Investigations were focused, therefore, at the Sigatoka Sand Dunes where Lapita ceramics had been recorded along a beach-front section by Birks (1973).

From about the Sigatoka Valley to the west, there are substantial areas of Pliocene sedimentary rocks, in the Sigatoka series and the Viti Limestones (Geological Map of Fiji, 1961). A second project investigated these potentially habitable caves, which in general would have been more accessible in this district of Viti Levu, where precipitation is lower than elsewhere and where natural vegetation was relatively light forest. As rock shelters often contain archaeological remains in sequence, a number of shelters were test-excavated to attempt to establish how early people had begun to use the coastal hinterland and interior. 


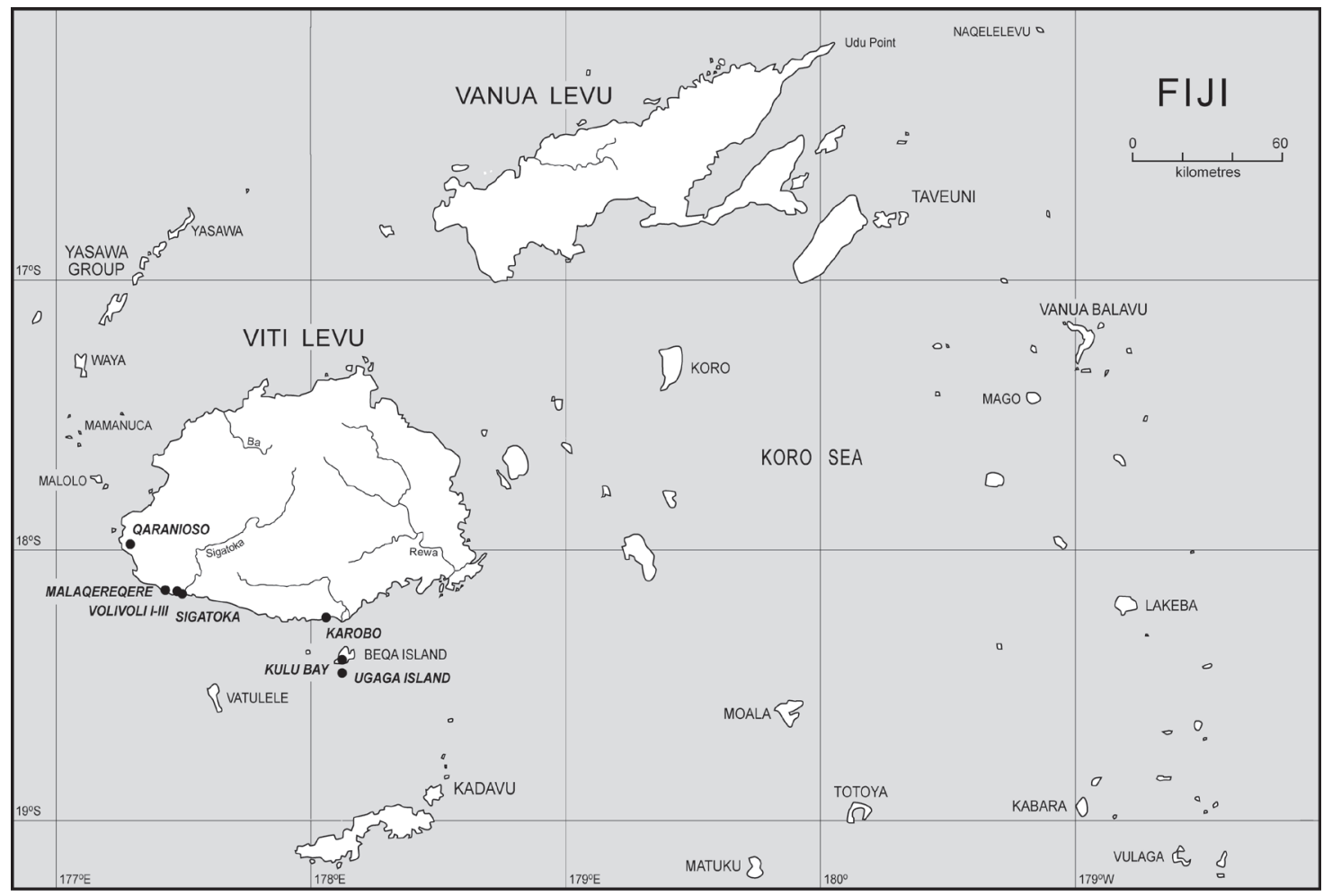

Figure 35. Map of Fiji showing research locations.

A third project was to analyse remains from the Karobo (VL 18/1) site held by the Fiji Museum. Karobo was excavated by Jack Golson, Bruce Palmer and others in the 1960s, and was an important site (Karobo was substantially destroyed by tourism development in 2002) as it yielded materials from the middle of the Fiji sequence. Fieldwork documents from the Karobo excavations were copied from the originals held at the Auckland Museum by Roger Green, and were used to determine site stratigraphy.

Beqa Island is the remnant of an eroded stratovolcano and lies $7.5 \mathrm{~km}$ south of the Navua Delta. The island has a maximum height of 480 metres above sea level and is conspicuous from the south coast of Viti Levu. In the 1980s, survey and excavation by Andrew Crosby (1988) recorded dentate-stamped sherds from four locations on Beqa, including Kulu Bay (BQ175A), and impressed sherds on Ugaga Island. A fourth project in 1997 aimed to recover larger samples of cultural material from these two sites than had been obtained from excavations in southern Viti Levu.

\section{Fieldwork in southern Viti Levu}

Sigatoka Dunes, VL 16/1

At the Sigatoka River mouth there is an extensive archaeological site (Sigatoka dunes site, VL 16/1), which has a sequence encompassing all the main phases of Fijian culture history. It has been the primary focus of research in Fijian archaeology, in fieldwork and in sequence analysis (Gifford 1951; Green 1963; Green and Palmer 1964; Dickinson 1968; Palmer et al. 1968; Birks 1973; Frost 1979; Southern 1986; Hunt 1986, 1987; Parry 1987; Best 1987a, 1989; Visser 1988, 1994; Crosby 1991, 1992; Hudson 1994; Petchey 1995; Burley 1997, 2003; Dickinson et al. 1998; Wood et al. 1998; Burley and Shortland 1999; Marshall et al. 2000; Burley and Dickinson 2004). 
As a prime settlement locality, the Sigatoka dunes site offered a chance to test the possibility raised by Southern (1986) and Gibbons (1985) that evidence of human activity might be earlier than predicted by the conventional archaeological sequence of Green (1963). It was hoped that archaeological deposits in limestone shelter and cave sites at nearby Volivoli, and in the middle reaches of the valley, might also contain sequences which would assist our understanding of early settlement patterns and, in particular, produce faunal and other organic remains which would help to fill out the archaeological evidence at the dunes, where these materials are very scarce. The main Sigatoka Valley and its lower tributaries also presented an ideal opportunity to investigate aspects of the early sedimentary and vegetational history of the district. We were interested in looking at the nature and timing of anthropogenic change in relation to the geomorphology of the dunes, including whether changes occurred in the hinterland early or later in relation to the cultural sequence, and whether substantial change was 'front-loaded' in the sequence, had occurred cumulatively or had increased over time. Investigation of another aspect of palaeoenvironmental change, the impact of people on indigenous vertebrates, was also favoured by the availability of limestone cave sites suited to palaeontological deposition. Abutting the inland edge of the Sigatoka dunes is the Volivoli limestone massif, and other formations equally riddled with caves exist upstream, notably the spectacular outcrops at Toga.

Our basic aim was to set the early archaeological sequence of the district, essentially the first millennium of habitation, into its local context of environmental change. Our methods included coring for sedimentary and palynological records and palaeontological investigations, which are reported in Chapters 2-4, and archaeological research, described here.

After frequent archaeological excavations at the Sigatoka dunes site over the past 50 years, a new phase was beginning in 1996 with a project by Simon Fraser University and the Fiji Museum (Burley 1997, 2003, 2005). Our research was restricted, therefore, to the most pertinent issues of our overall project, those concerning the colonising status of Lapita remains at the site. Did Level 1 (Birks 1973) represent the first human habitation at the site, or was it only the earliest archaeological horizon to survive in a volatile sedimentary sequence? This is an important question from several points of view concerning colonisation. One is whether landscape preferences in the early Lapita era had included the large river valleys, route ways into the interior and obvious sources of many kinds of resources, yet not at all conspicuous among known Lapita site locations. None are recorded from the Rewa Valley; Natunuku, a site of early Lapita facies, stands fairly close to the mouth of the Ba River but not directly at it, while the Sigatoka Lapita site is at the river mouth but has ceramics and radiocarbon dates largely indicative of fairly late Lapita occupation. The question also bears importantly on the relationship of human habitation to the development of the dunes, and especially on whether the dune formation is substantially anthropogenic through the impact of people, by deforestation, on the sedimentary regime.

The main issue was devolved into several operational questions about the lower levels of the stratigraphy at the Sigatoka dunes. Was it possible to determine whether any remains of earlier human activity underlay the Level 1 palaeosol? Was the Lapita occupation contemporaneous with the stable (Level 1 palaeosol) phase or did it begin only after a significant period of soil formation, i.e. later than there existed a suitable locality for settlement? We sought to recover archaeological materials suitable for establishing the age of Lapita occupation at the site by radiocarbon dating, and to compare those results with others obtained on samples of sand by OSL dating (Anderson et al. 2006). The sand samples would provide a sedimentary chronology that began before and spanned the phases of soil formation. Those had been described by Birks (1973) according to a basic stratigraphic profile encompassing three periods of occupation, 
Levels 1-3, marked by the association of cultural remains with phases of soil development. The simplicity of that model has been challenged by Marshall et al. (2000), but it remains the most useful description of the greater part of site VL 16/1, certainly for comparative purposes with earlier research results, irrespective of the validity of Marshall et al.'s (2000) views on the age and origin of dune building.

In 1996, we sought a representative stratigraphic sequence and decided to concentrate on an area which began at about the 1200 foot point in the Birks' excavation, which is approximately at the $500 \mathrm{~m}$ datum in the 1992 site survey plan (Marshall et al. 2000:Fig. 5.1), and which extended east to the western boundary of the main burial areas investigated by Best (1987a, b, 1989). These lie immediately east of the Marshall et al. (2000) datum point at $200 \mathrm{~m}$. Our choice of this area was strongly influenced by the results of an archaeological salvage project two years earlier, after severe damage to the seaward dunes in this area by cyclone Kina. Hudson's (1994) report suggested both that Levels 1 and 2 ran through this area, though they were difficult to separate, and that the ceramics from the lower horizon included early Lapita types (Petchey 1994) not previously reported from Sigatoka.

Located in very mobile sand dunes which extend for several kilometres along a high-energy beach front, the Sigatoka dunes site is constantly changing and few of its archaeological features remain visible from year to year. So by 1996, the exposures investigated by Hudson (1994) were well covered by recent sand deposition and none of the surface features she recorded remained recognisable. The difficulty of re-locating her excavations was compounded by survey problems in the available site plans. These consisted of an early version of the 1992 survey plan of the Sigatoka site, which was both extensive and detailed (later versions were made available as Wood et al. 1998 and Marshall et al. 2000), and Hudson's localised plans based on it. The latter indicated that the centre of the 1993 excavations, as represented by profile 2, lay about $60 \mathrm{~m}$ east of the $500 \mathrm{~m}$ datum of the 1992 plan (Hudson 1994:Figure iii). This put the 1993 salvage excavations seaward of a prominent remaining area of Level 2 palaeosol which could be recognised on the ground and in the 1992 survey map. Coring soon showed that the assumed Hudson excavation area had been washed out and refilled by recent sands and that no clearly recognisable Level 1 horizon could be found below the adjacent Level 2 exposure. However, we were not confident about this result because Hudson (1994:Figure ii) shows the centre of the 1993 excavations about $150 \mathrm{~m}$ east of the $500 \mathrm{~m}$ datum, not $60 \mathrm{~m}$, as in Figure 36. We cored transects in this area as well, with similar results, on the assumption that the datum shown in Hudson (1994) ought to be $400 \mathrm{~m}$ not $500 \mathrm{~m}$.

These difficulties should have been resolvable by reference to the 1992 survey map, but that also contained an error. It was apparent as soon as we sought to match the map to the distribution of recognisable features on the ground, initially by tape measurement and later by total station survey, that the distances were substantially different (see also Burley and Dickinson 2004:note 2). Despite considerable effort using aerial photos, we could not resolve this problem in the field. The 1992 survey map was not keyed to an adequately described site datum feature, the site datum lay $60 \mathrm{~m}$ or so outside the boundary of the printed map, and the $100 \mathrm{~m}$ datum marker poles had been washed away (these deficiencies remain in Marshall et al. 2000). Consequently, it was not possible in 1996 to fix the 1992 survey precisely on the ground. From the later versions of the map (Wood et al. 1998; Marshall et al. 2000), it is now apparent that the version available to us in 1996 had been produced, in error, about 25\% larger than its scale.

In the light of these difficulties, the essential features in the area of interest were re-mapped by total station survey (Figures 36-37) and tied to the fixed location of the Club Masa buildings. A sand corer with a diameter of $100 \mathrm{~mm}$ was then used to attempt to locate a suitable area for 


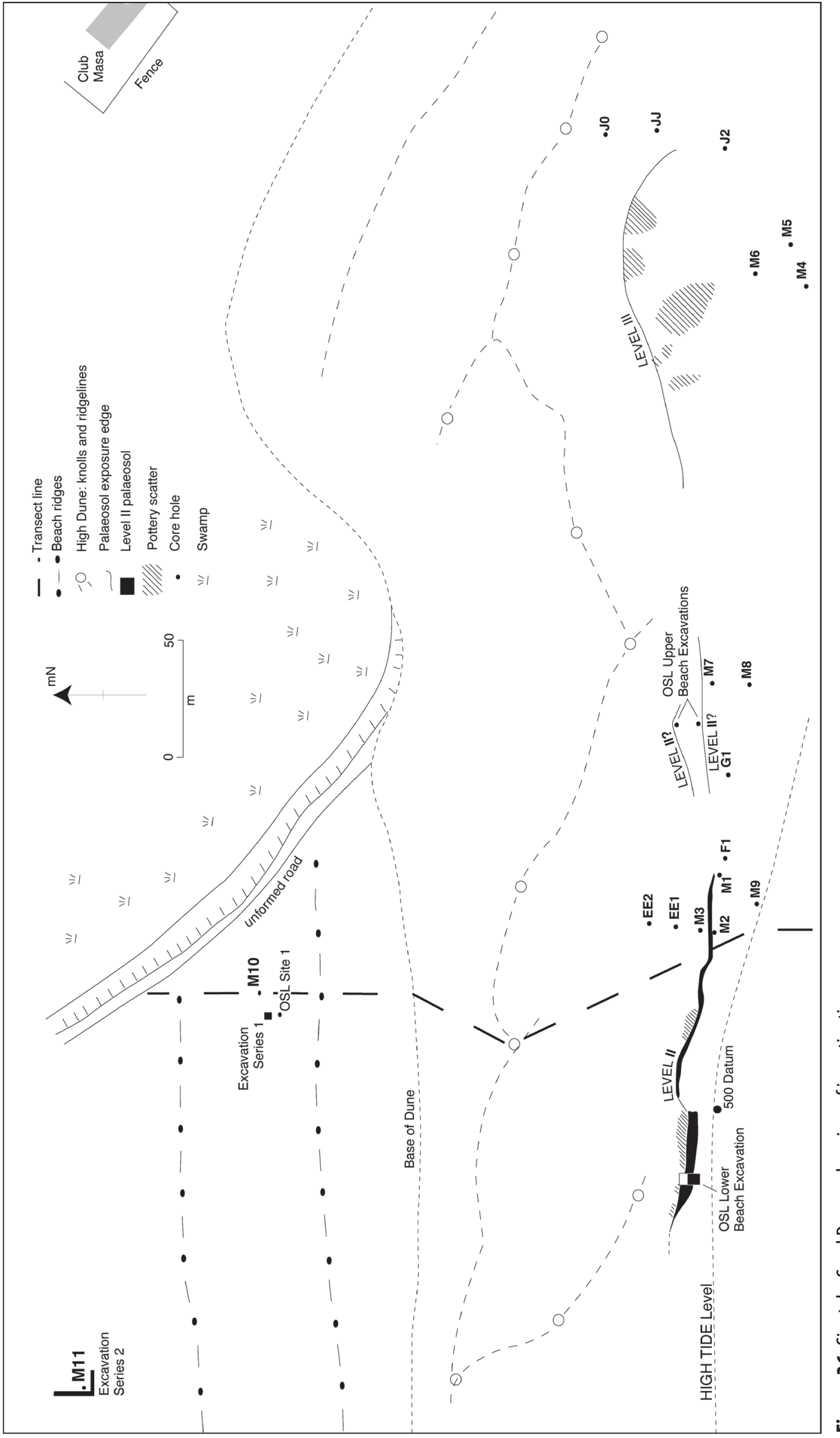




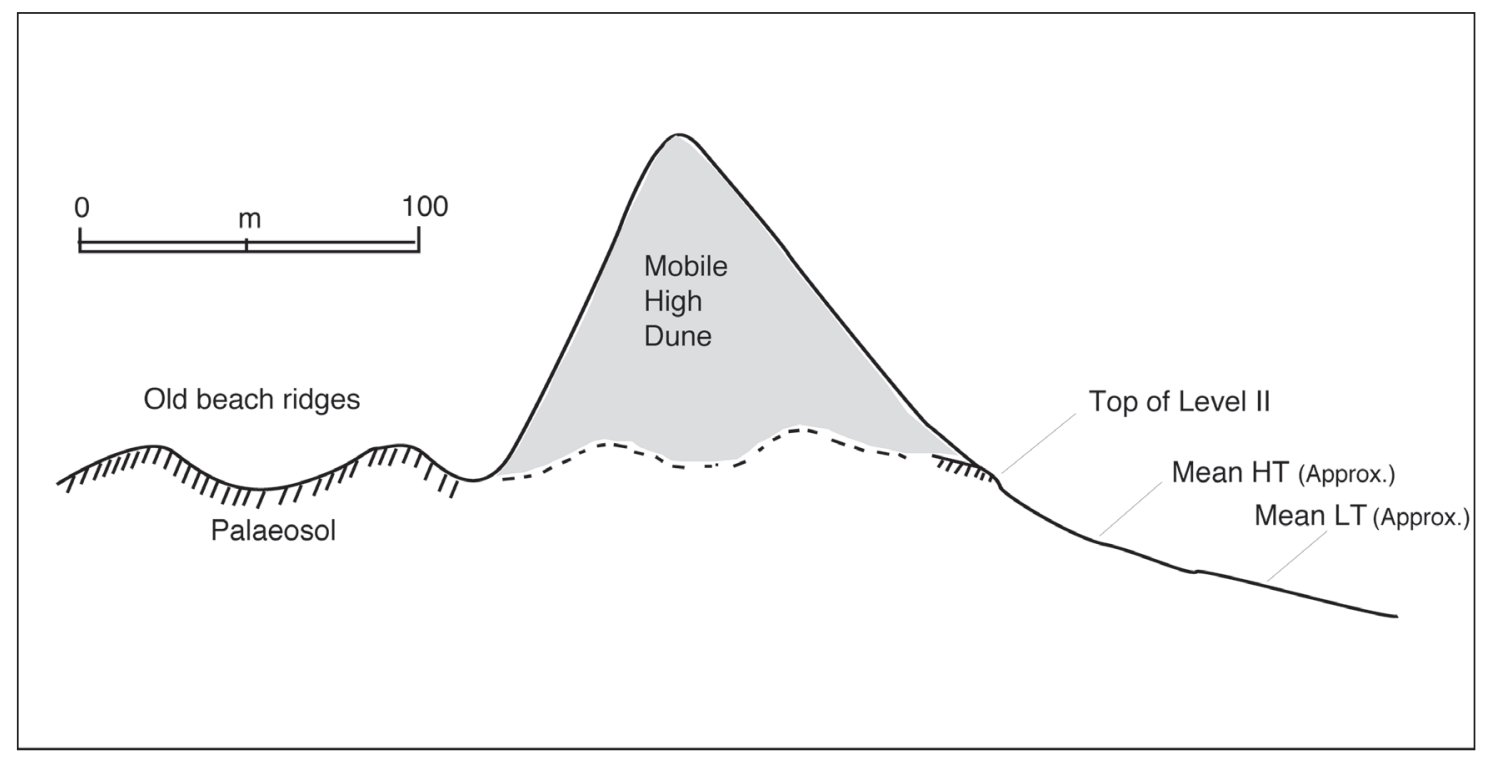

Figure 37. Sigatoka Sand Dunes, cross-section of dune system. Note vertical scale is exaggerated.

detailed investigation and sample collection. Eighteen cores were drilled, recorded and mapped (Figure 36), most going down to about $5 \mathrm{~m}$ or to the water table, where sediments could no longer be recovered satisfactorily. The most informative results are from cores which were started in compact, brown sands or weakly developed soils containing in their upper levels, or deposited immediately on them, ceramics of Navatu phase types, notably pieces of leaf-impressed trays and paddle-impressed pot sherds (Figure 38). The pedogenic horizon is assumed to be Level 2 of Birks (1973) where it is exposed in the seafront dunes and to represent it, perhaps more complexly and less exclusively, in the sand plain behind it.

The cores show a broadly uniform stratigraphy but differences in colour between the various sand units at Sigatoka are difficult to interpret and some may have no significance beyond exposure time. Marshall et al. (2000:21) note that even moist green-brown sands, found at depth, dry to yellow-brown and then yellow. Some differences in colour also reflect the degree of iron sand admixture which is variable and unpredictable. It was really only weathering and organic enrichment at periods of stability and pedogenesis which provided horizons that can be readily traced stratigraphically and geographically.

Below the Level 2 palaeosol, there is a layer of relatively uncompacted sand, finely laminated, which varies from yellow-brown or buff near the top to yellow-grey below. This overlies darkbrown to khaki-coloured or green-brown sand which is weakly compacted and which, on various grounds, we eventually concluded was the Level 1 horizon. It lay at about the right elevation relative to approximate high tide for Level 1 . In the top $30 \mathrm{~cm}$ or so it contained slight evidence of organic enrichment (cf. Burley and Shortland (1999:35) who also noted the weak soil development in Level 1). Quantities of small yellow-to-orange pebbles of pumice occurred mainly near the surface of the layer and these had been associated with Level 1 by Hudson (1994), and Matararaba (pers. comm., Fiji Museum). The Level 1 attribution also seems very probable in light of the conclusion by Marshall et al. (2000:21) that ' . . the green-brown moist sand proved a universal base beneath Level 1 and occasionally beneath Level 2. It was never found between Levels 1 and 2.' Since our cores went through Level 2 at the surface, the greenbrown sand in them must signify Level 1, on that basis. However, we recovered no diagnostic ceramics by coring and were doubtful at the time whether cultural remains of Level 1 still existed in the area we investigated, following the devastation wrought by cyclone Kina (Anderson et 


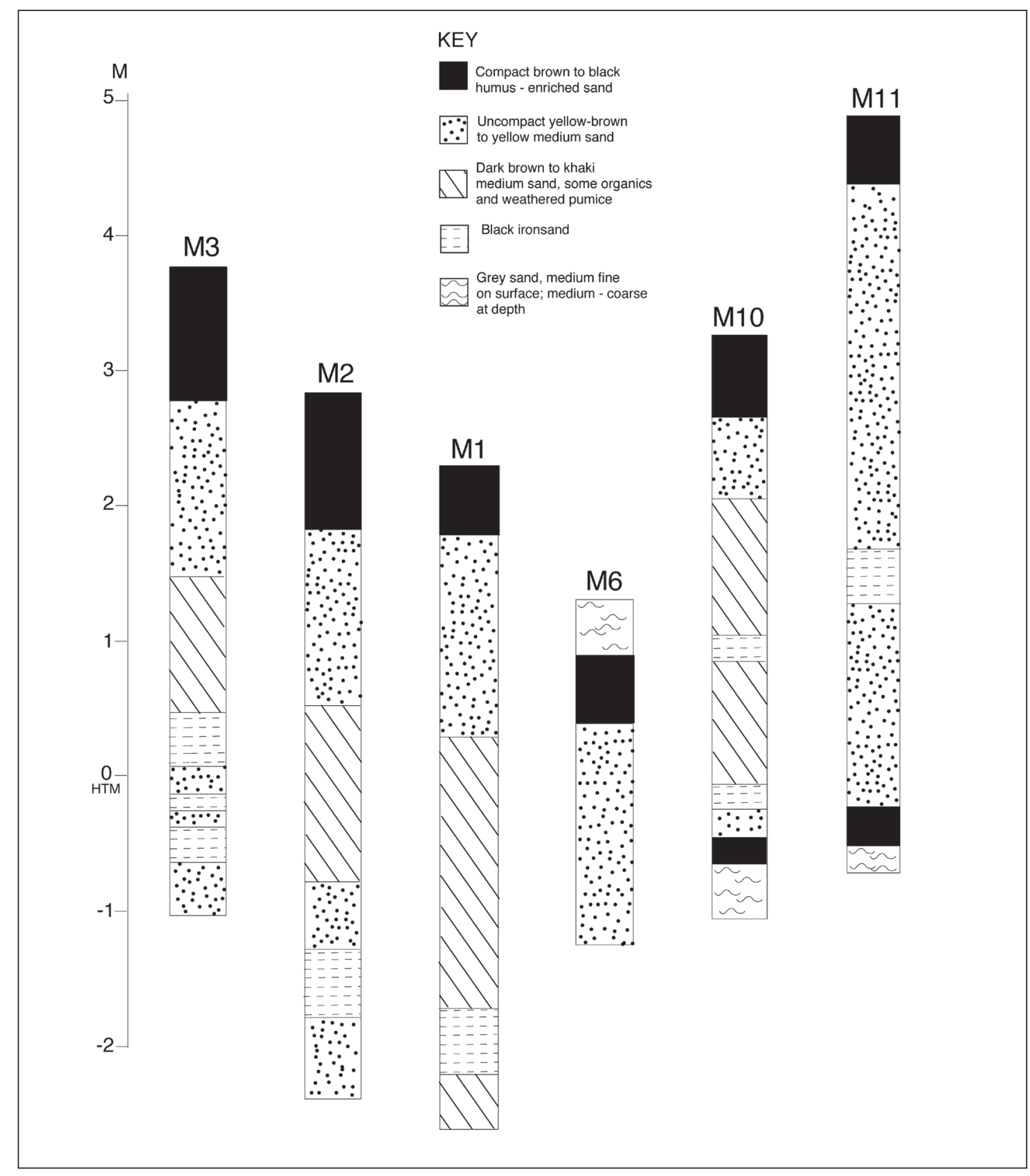

Figure 38. Sigatoka Sand Dunes, core results.

al. 1996). It seems, additionally, that Level 1 has always been less extensively evident in the area of our investigations. According to Marshall et al. (2000:24), it was generally absent as an outcropping horizon containing cultural material from about 300 to $640 \mathrm{~m}$ on their map, and was conflated with Level 2 at 400 to $500 \mathrm{~m}$. Nevertheless, while cultural material was sparse or missing in the area, there seems little doubt that we recorded and sampled a sequence which included Level 1 and Level 2.

Below the assumed Level 1 unit were bands of yellow-grey to yellow-brown sands interspersed with bands and lenses of black iron sand. No Level 1 unit was encountered in the area of low ground cored by M4 to M6 (Figure 36), and in the sand-plain cores (M10, M11) there were some slight variations, including organic enrichment of a thin layer, perhaps an old incipient soil horizon, but of unknown age or situation in the Sigatoka sequence, at about $5 \mathrm{~m}$ depth (Figure 38). 
De Biran's (2001) recent analysis of the geomorphology of the Sigatoka dunes and sand plain has proposed a sequence of formation similar to that outlined by Dickinson et al. (1998). According to de Biran, the present sand plain (or, more precisely, 'strandplain', de Biran 2001:41) in the Sigatoka delta was built as a series of sand ridges accreting seaward, a process beginning about the mid-Holocene. Level 1 represents a period of stability and soil formation, beginning approximately $900 \mathrm{BC}$, on the back-beach of the prograding delta. It was buried by a new episode of sand deposition, possibly early in the first millennium $\mathrm{AD}$, on which, about $\mathrm{AD} 350$, there began to develop the deep and extensive Level 2 soil. This covers the entire sand plain and outcrops at the seafront of the dunes. After about the 7 th century AD, it was covered near the coast by the beginnings of the high dune development, in which, at intervals rather than as a single phase, there was patchy development of the Level 3 soil, beginning about the 14th century AD.

As well as this interpretation, there are some minor (Dickinson et al. 1998) or major (Marshall et al. 2000) variations in earlier works. Marshall et al. (2000) suggest that the settlement sequence at Sigatoka was more complex and continuous than is allowed in the conventional model although they continue to find that necessary to their exposition; and that dune building had begun very early in the sequence, probably before initial human occupation. This is potentially an important argument, from several points of view which they canvass, but the evidence on which it is based, especially the uncertain identification and provenance of early ceramics at relatively high points in the dunes west of the main archaeological site areas, is open to question. We agree with Hudson (1994:12) and Marshall et al. (2000) in regarding at least Level 2 as having developed on a fairly strongly undulating surface. Our cores show variation of 3-4 m height in the lower boundary of Level 2 at the dunes' front (Figure 38), and there is at least $2 \mathrm{~m}$ of height variation in the upper surface of the sand ridges behind the dunes. Nevertheless, this is still comparatively low relief and hardly indicative of the kind of dune-building evident in the modern parabolic forms. The geomorphological model of Dickinson et al. (1998), substantially confirmed by de Biran (2001), has proven the most plausible in interpreting the archaeological and chronological evidence (Burley 2003; Burley and Dickinson 2004; Anderson et al. 2006).

\section{Test excavations in rock shelters}

Volivoli shelters

Approximately $1.5 \mathrm{~km}$ inland from the coast and the same distance west of the Vatueta distributary of the Sigatoka River is Volivoli village. Running immediately behind it along the western edge of the delta plain is an ancient channel of the Sigatoka River, and above that loom the Volivoli bluffs. They are on the edge of a $250 \mathrm{~m}$ high spur of fossiliferous Tertiary limestones and sandstones which dip seaward at 15-20 (Sawyer and Andrews 1901:92; see also Gilbert 1984:114). The southern margin of the spur abuts the inland edge of the Sigatoka dunes, forming a saddle through which pass the railroad and the Queen's Highway. Around the periphery of the spur and in dolines on its upper surface are numerous caves and shelters. Some of these have been investigated in pursuit of subfossil faunal remains (Chapters 2-3). Archaeological investigations consisted of test excavations in three sites (Figure 39), with the primary purpose of establishing occupation sequences.

\section{Volivoli I}

A small shelter is formed by a cluster of large boulders at the base of the bluffs adjacent to the Volivoli swamp. A test excavation of a $0.5 \mathrm{~m} \times 1.0 \mathrm{~m}$ test pit disclosed a shallow deposit of a 


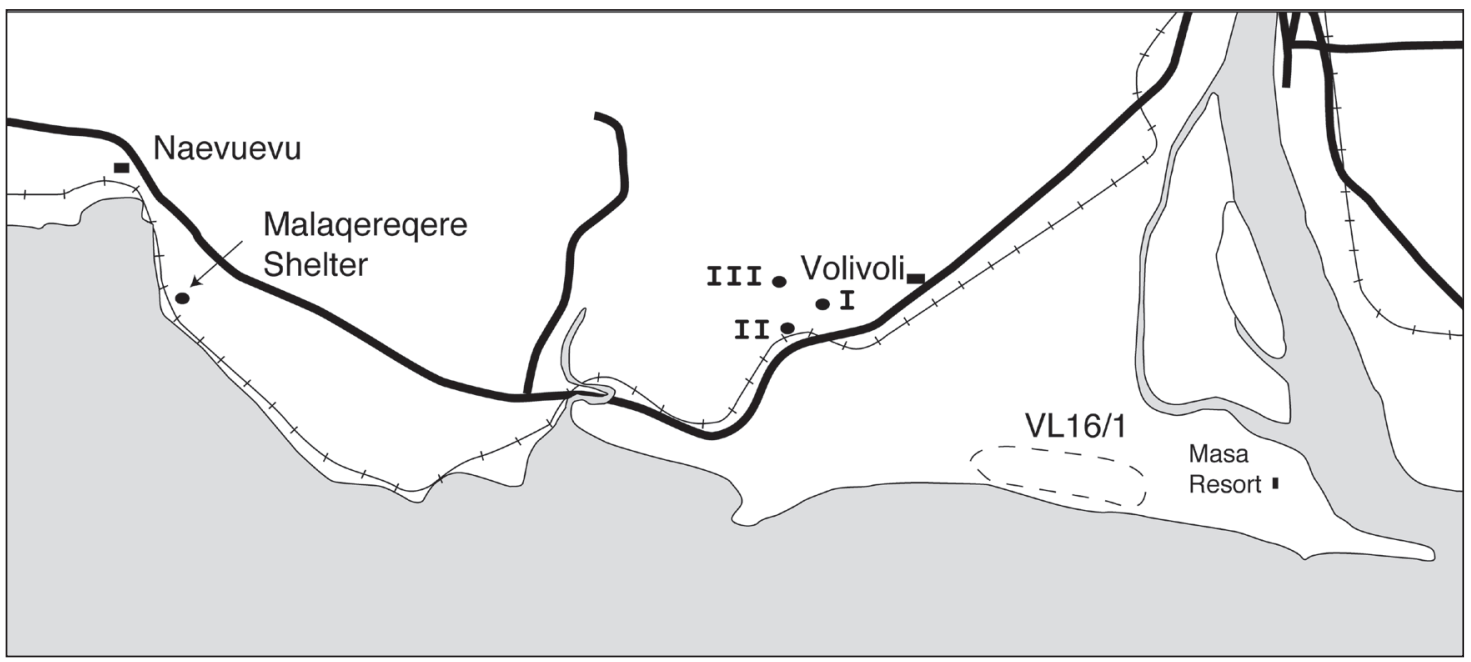

Figure 39. Location of Volivoli and Malaqereqere shelters.

damp, sticky, dark-brown to black loam (Layers 1 and 2) overlying weathered carbonate grit (Layer 3) (Figure 40). The shelter surface is only $0.5 \mathrm{~m}$ above the ground surface of the swamp. Small quantities of shell, bone and pottery were recovered by wet-sieving through $3 \mathrm{~mm}$ mesh.

\section{Volivoli II}

On the southern edge of the Volivoli bluffs, a rock shelter, formed by very large boulders, lies $14 \mathrm{~m}$ north of the railroad, at $106 \mathrm{~m}$ from the northern buttress of the rail bridge over the Queen's Highway. The rock shelter is $15 \mathrm{~m}$ long and about $2 \mathrm{~m}$ wide for most of its length. An excavation of a $1.0 \times 1.5 \mathrm{~m}$ unit was made at the middle of the shelter (Figure 41). The excavation was by $10 \mathrm{~cm}$ spits within natural layers and all material was sieved. For Layer 1 it was possible to use a $3 \mathrm{~mm}$ sieve, but for Layers 3, 5 and 6 the stiff, dense clay resisted anything but the $6 \mathrm{~mm}$ sieve. Stratigraphy in this was as follows:

Layer 1: Fine, dusty, mid-brown loam containing pottery, some roof-fall and candlenut fragments, $0-12 \mathrm{~cm}$.

Layer 2: A grey-white calcite layer extending discontinuously at $12-17 \mathrm{~cm}$.

Layer 3: Mid-brown clay loam, stiff and slightly damp. Contained scattered charcoal, pottery, shell and small limestone clasts.

Layer 4: A grey-white discontinuous calcite band, $2 \mathrm{~cm}$ thick, which sloped from $44 \mathrm{~cm}$ to $63 \mathrm{~cm}$ across the west baulk.

Layer 5: Below the calcite, a stiff, orange-to-red clay loam packed with roof-fall and boulders up to $50 \mathrm{~cm}$ maximum length. This extended to $110 \mathrm{~cm}$, but pottery and other cultural material disappeared at $80 \mathrm{~cm}$.

Layer 6: From $110 \mathrm{~cm}$ to $130 \mathrm{~cm}$, at which point the base of the deposit was reached in weathered, yellow limestone. A red-brown clay loam and gravel with relatively few larger limestone clasts. Several sherds were recovered at 110-115 cm.

Variation in the stratigraphy, including in the nature of the material and its colour, and in the existence of two calcite layers, suggested that Volivoli II represented a relatively long and varied occupational sequence, broken at intervals by periods of abandonment. 


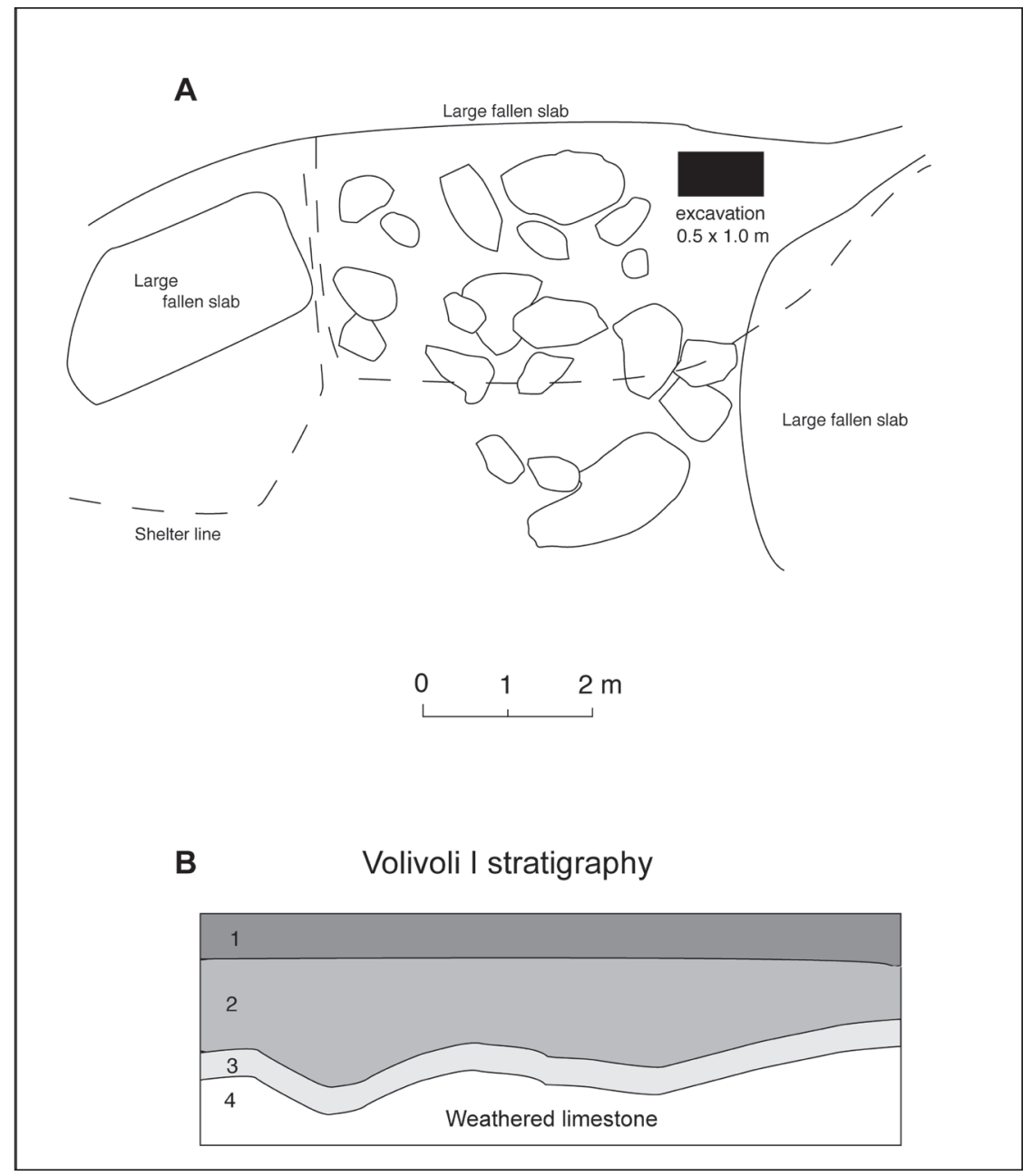

Figure 40. Volivoli I, plan of shelter (A) and excavation section (B).

\section{Volivoli III}

Directly above the Volivoli fossil site 2, named Qaranivokai, there is a small rock shelter formed in a doline. A $1.0 \mathrm{~m} \times 1.0 \mathrm{~m}$ test pit was excavated in the floor of this shelter (Figure 42). Excavation was by $10 \mathrm{~cm}$ spits in natural layers. Material to $30 \mathrm{~cm}$ was sieved to $3 \mathrm{~mm}$, but below that level to $6 \mathrm{~mm}$. Below $30 \mathrm{~cm}$ depth, the excavation area was reduced by half. The stratigraphy was as follows:

Layer 1: Dark-brown, friable to blocky clay loam, with abundant fire-cracked stone, shell and pottery and small amounts of bone. At 10-12 cm were several calcite lenses. The soil became more blocky and clay-rich with depth. A 3-5 cm thick white ash at 35-40 cm. Adhering to its base were numerous pieces of charcoal.

Layer 2: Medium-brown fine sediment with abundant fragments of limestone from $45 \mathrm{~cm}$ to $80 \mathrm{~cm}$ depth. Cultural material sparse and diminishing with depth.

Layer 3: From $80 \mathrm{~cm}$ to $110 \mathrm{~cm}$ an orange-brown blocky clay with abundant limestone clasts and boulders. Some shell and pottery but scarcely any bone or charcoal was found down to $80 \mathrm{~cm}$, where several calcite lenses were encountered. Below the calcite lenses was a tough, yellow-orange clay containing numerous pieces of limestone and no cultural material. It ran out on a flowstone or limestone floor which could not be penetrated. 


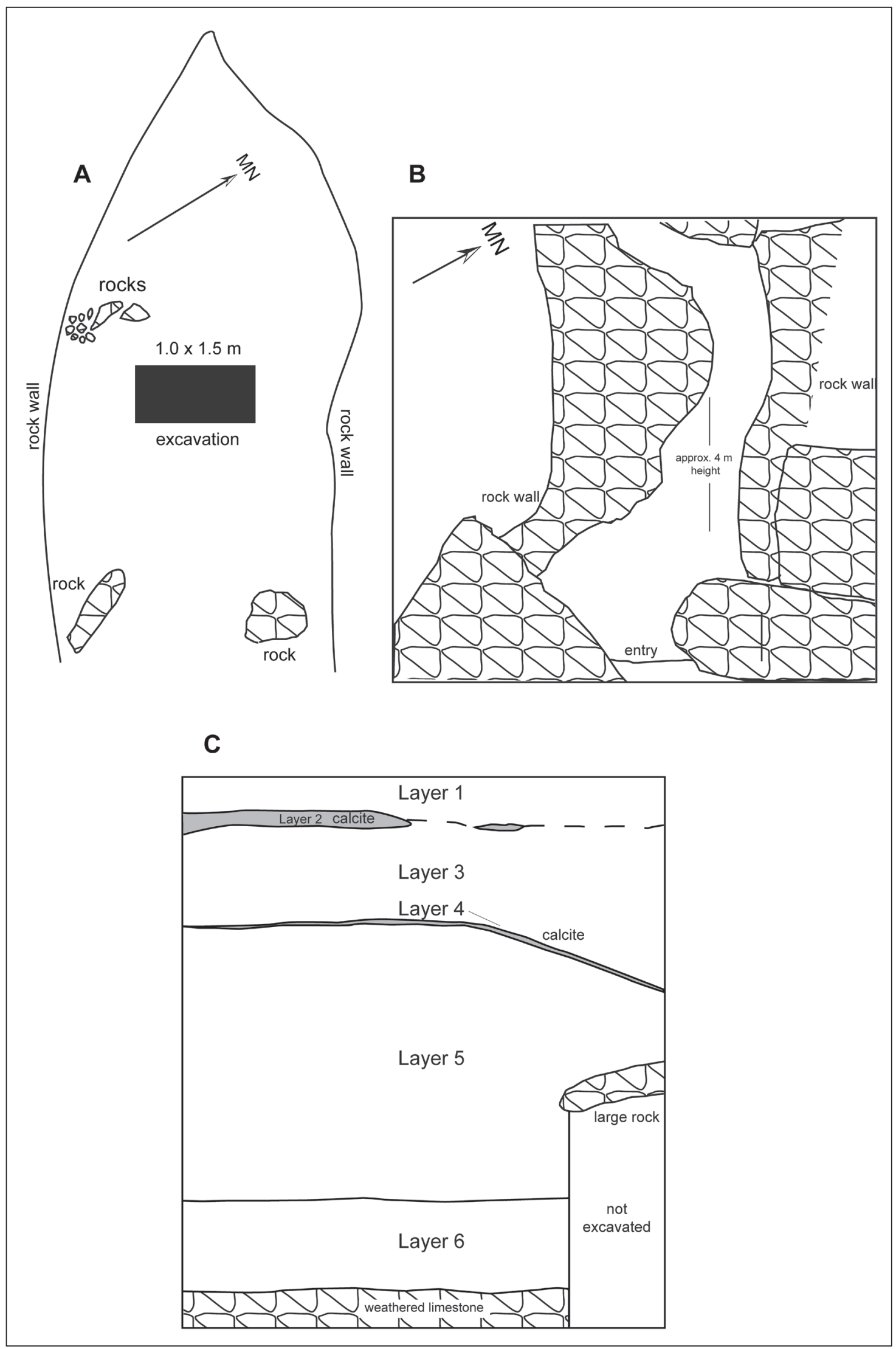

Figure 41. Volivoli Il, plan of shelter (A), front entrance (B) and excavation section (C). 


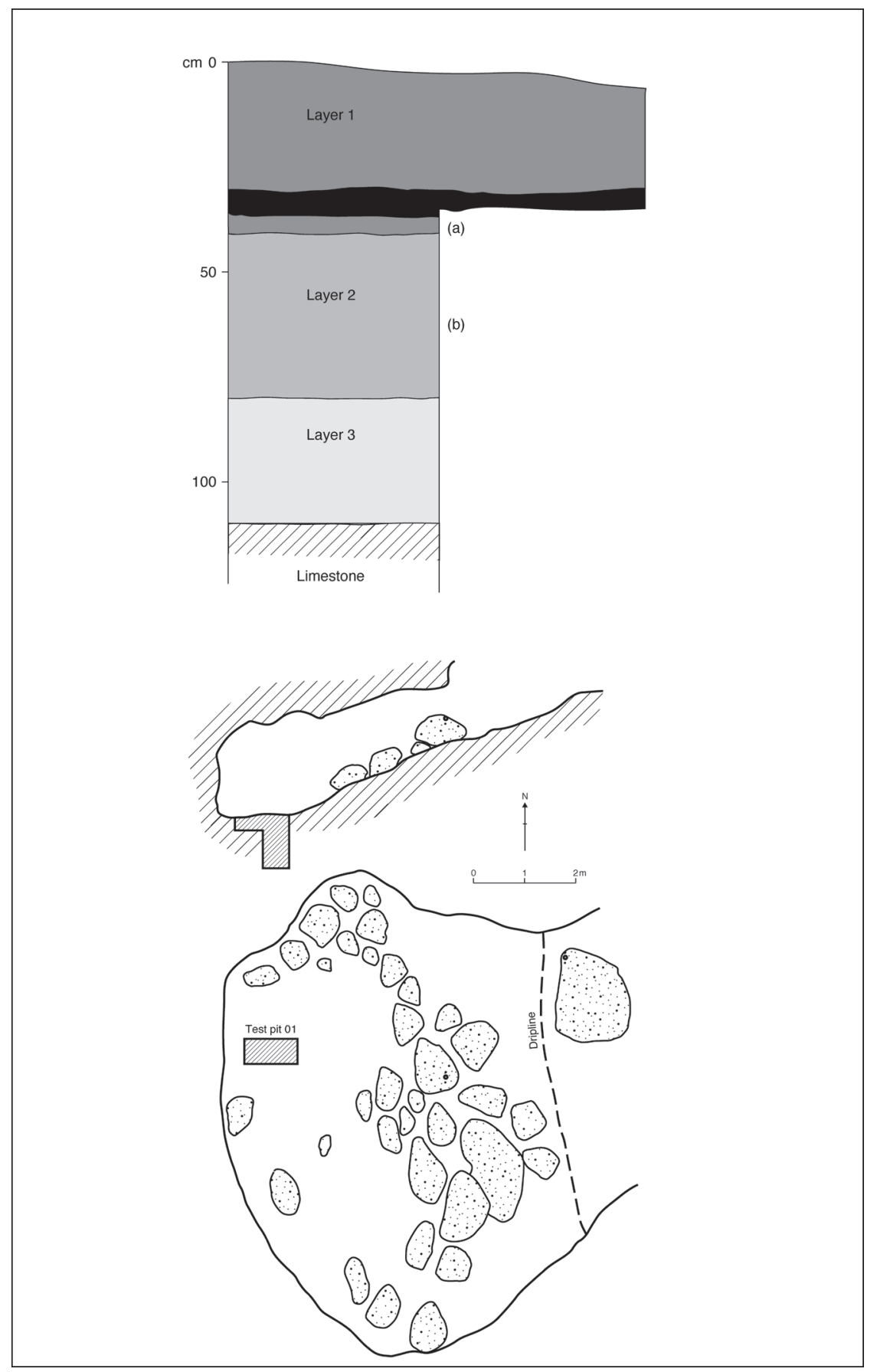

Figure 42. Volivoli III, plan (bottom) and profile of shelter (middle) and excavation section (top).

\section{Malaqereqere shelter}

This is a south-facing rock shelter located $1 \mathrm{~km}$ east of Naeuvevu village along the railway line (Figure 43). The shelter entrance is $12 \mathrm{~m}$ above the lagoon and $21 \mathrm{~m}$ north of the railroad cutting. At the entrance of the shelter is a $2 \mathrm{~m}$ wide flat, separated from an inner chamber, $10 \mathrm{~m}$ x $6 \mathrm{~m}$, by a low wall of placed stones. A $1 \mathrm{mx} 2 \mathrm{~m}$ excavation was laid out behind the rock wall (Figure 44). Excavation was by $10 \mathrm{~cm}$ spits, but followed the main layer changes, and material was sieved to $3 \mathrm{~mm}$.

The stratigraphy was too finely complex in detail (Figure 44) to follow by stratigraphical excavation in plan. It consisted mainly of alternating thin layers and lenses, $0.5-5 \mathrm{~cm}$ thick, often disturbed by crab holes, of a soft, friable, brown to black loam and compact white to 


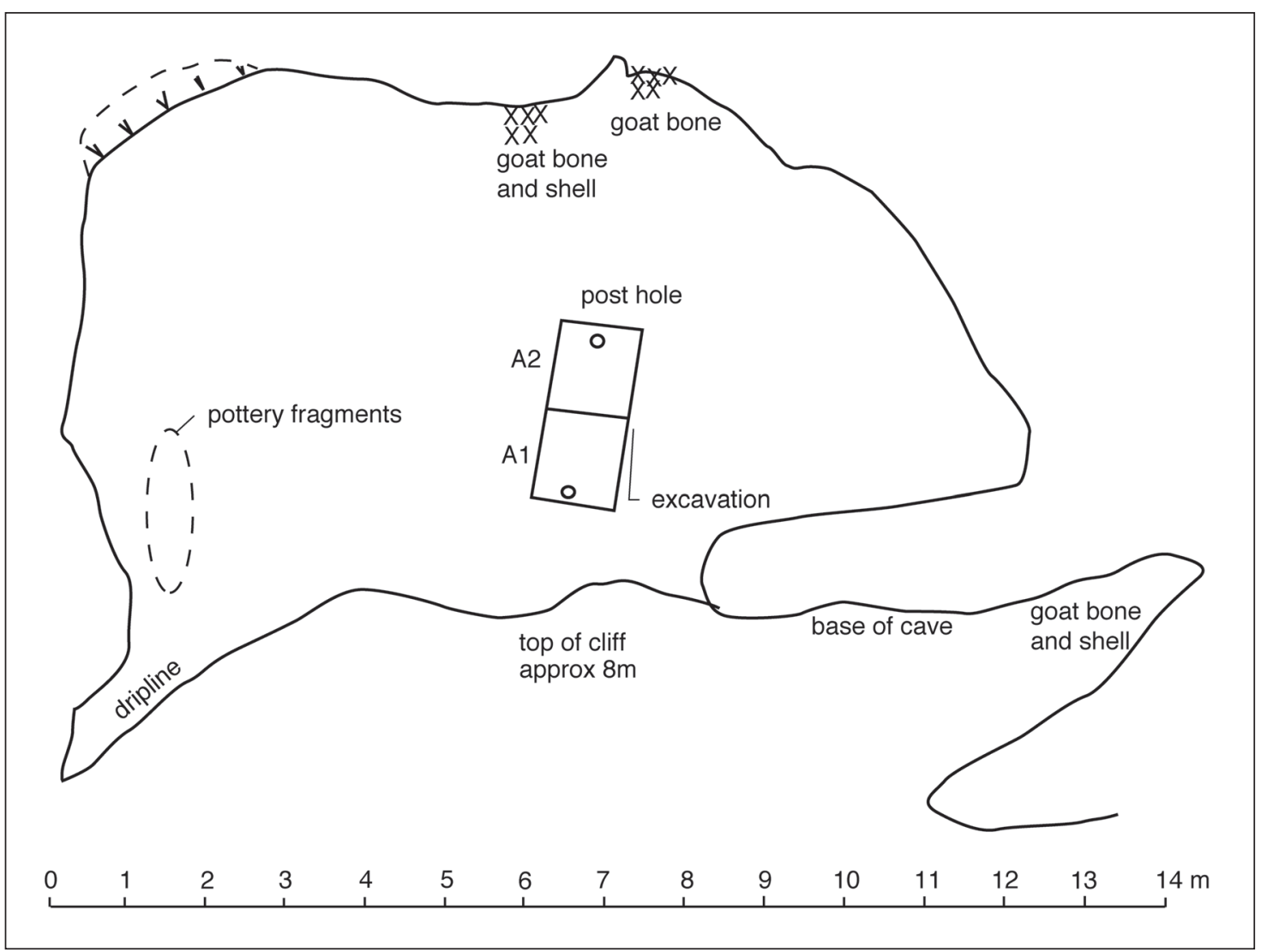

Figure 43. Malaqereqere, plan of shelter.

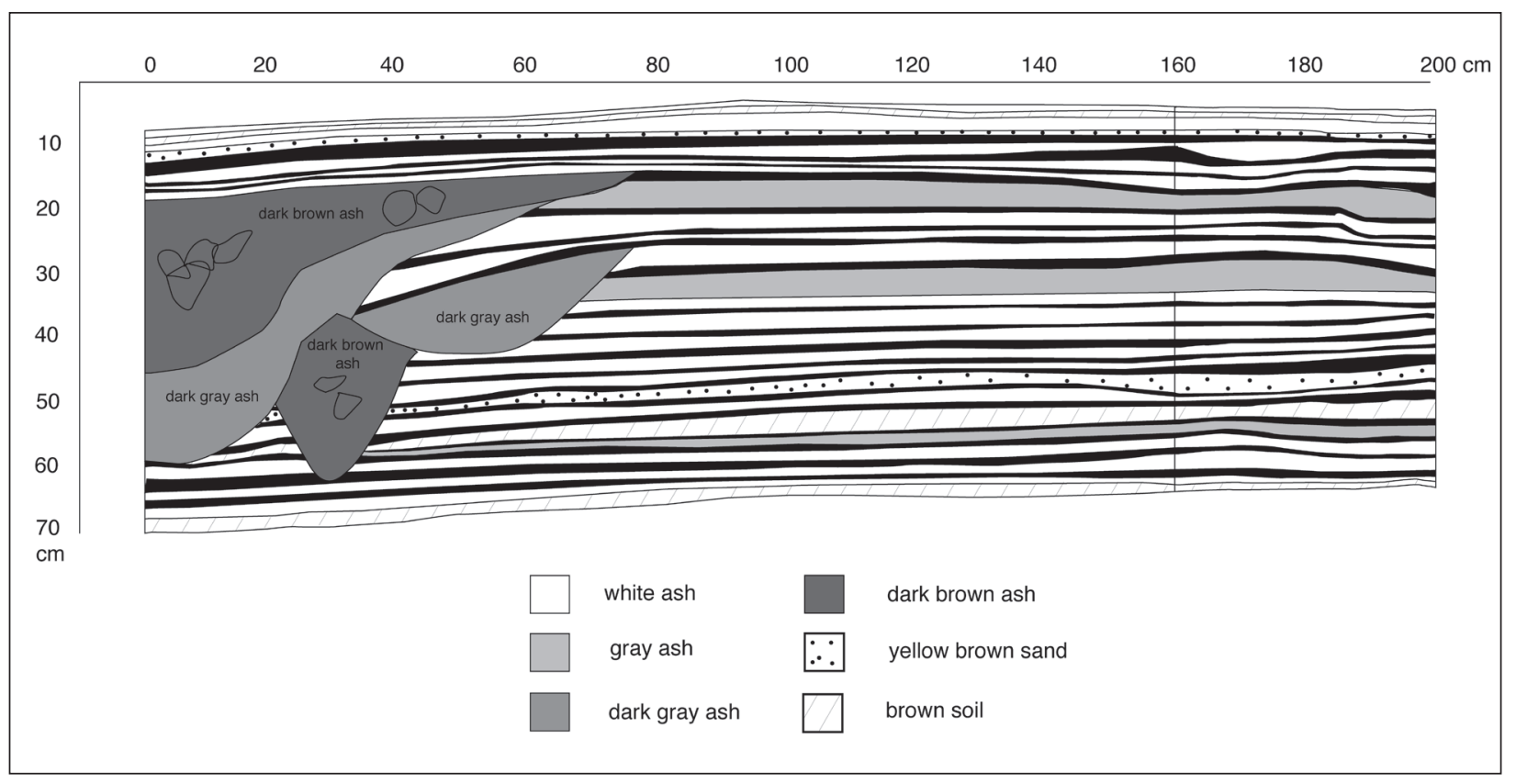

Figure 44. Malaqereqere, excavation section. 
grey ash. At 40-50 cm, and again at 50-60 cm, the loam units were separated by yellow-brown sand. The base of the excavation, which reached to $68 \mathrm{~cm}$, was formed by a flat, impenetrable, limestone floor. In Square A1, there was extensive disturbance resulting from the construction of a series of inter-cutting ovens. That aside, the main stratigraphy was as follows:

Layer 1: $5-15 \mathrm{~cm}$ (site datum was $5 \mathrm{~cm}$ above the surface). Consists of thin brown and white foliations of ash and loam, the ash containing much calcined shell which fell into dust at contact.

Layer 2: $15-25 \mathrm{~cm}$. Similar to Layer 1 but separated from it by a spread of continuous white ash, approximately $3 \mathrm{~cm}$ thick, containing charcoal and fine black foliations.

Layer 3: $25-50 \mathrm{~cm}$. Similar appearance but separated from Layer 2 by a continuous spread of black ash and charcoal, $2 \mathrm{~cm}$ thick. Layer 3 also contained remnants of a small oven in Square A1, marked by ash, charcoal and burnt coral. At the base of this layer is a continuous thin spread of yellow-brown sand.

Layer 4: $50-55 \mathrm{~cm}$. Mostly yellow-brown sand lenses separating thin foliations of brown loam and grey ash, with one $2-3 \mathrm{~cm}$ loam layer extending the length of the excavation and separating this unit from Layer 5 .

Layer 5: 55-68 cm. Similar material to Layer 4. At the base of the site there is a thicker $(5 \mathrm{~cm})$ lens of brown loam containing charcoal, ash and bone.

There were faunal remains throughout the layers, but in the ash, especially, were calcined and finely fragmented molluscan and crab shell and echinoderm spines. Fish bone occurred sparsely. Pottery was scattered throughout the deposit, mostly in the brown loam, and it was mostly thick-walled material from deep bowls and straight-sided vessels.

\section{Qaranioso shelters}

Large caves and shelters lie high up in a $300 \mathrm{~m}$ high limestone massif in the Tau district (Figure 35). Some of the caves have been mined for guano. Two small test excavations were undertaken.

\section{Qaranioso I}

This is very large cave, still inhabited by substantial colonies of swiftlets. Immediately inside the entrance is a steeply sloping sedimentary face going down approximately $5 \mathrm{~m}$ to the main cave floor, the latter covered in deep guano. The face was formed by guano mining. A re-faced section disclosed the following stratigraphy (Figure 45):

Layer 1: 0-80 cm of stiff, red-brown clay containing sparse shell (Anadara, Turbo), some fish spines and charcoal. A few plain body sherds were recovered. At $30 \mathrm{~cm}$ depth was a small hearth, which was sampled for charcoal.

Layer 2: $80-140 \mathrm{~cm}$ of loose brown guano. This contained no cultural material and a probe showed that it continued down for at least another $70 \mathrm{~cm}$.

\section{Qaranioso II}

About $20 \mathrm{~m}$ below Qaranioso I is another, but much smaller cave. It is bell-shaped and open at the top but has substantial shelter around the sides and near the entrance (Figure 45). A $0.5 \mathrm{~m}$ x $1.0 \mathrm{~m}$ test pit was excavated in the entrance shelter, by $10 \mathrm{~cm}$ spits, with sieving to $4 \mathrm{~mm}$ for all material, but to $2 \mathrm{~mm}$ for that which contained small bone. The stratigraphy was as follows (see also Anderson et al. 2000): 
Layer 1: $0-13 \mathrm{~cm}$ of powdery silt containing abundant pottery and shell. The layer terminates in a thin calcite or ash.

Layer 2: 13-49 cm. An orange-brown friable silty-loam, containing large pieces of limestone, marine shell, bird and reptile bones and abundant pottery.

Layer 3: $49-53 \mathrm{~cm}$ at west end of the trench, $50-65 \mathrm{~cm}$ at east end. Soft chalky calcite containing many limestone concretions and pebbles, plus large ?land snail shells and some reptile, rat and bat bone.

Layer 4: Extends down to at least $90 \mathrm{~cm}$. Loose, brown guano.

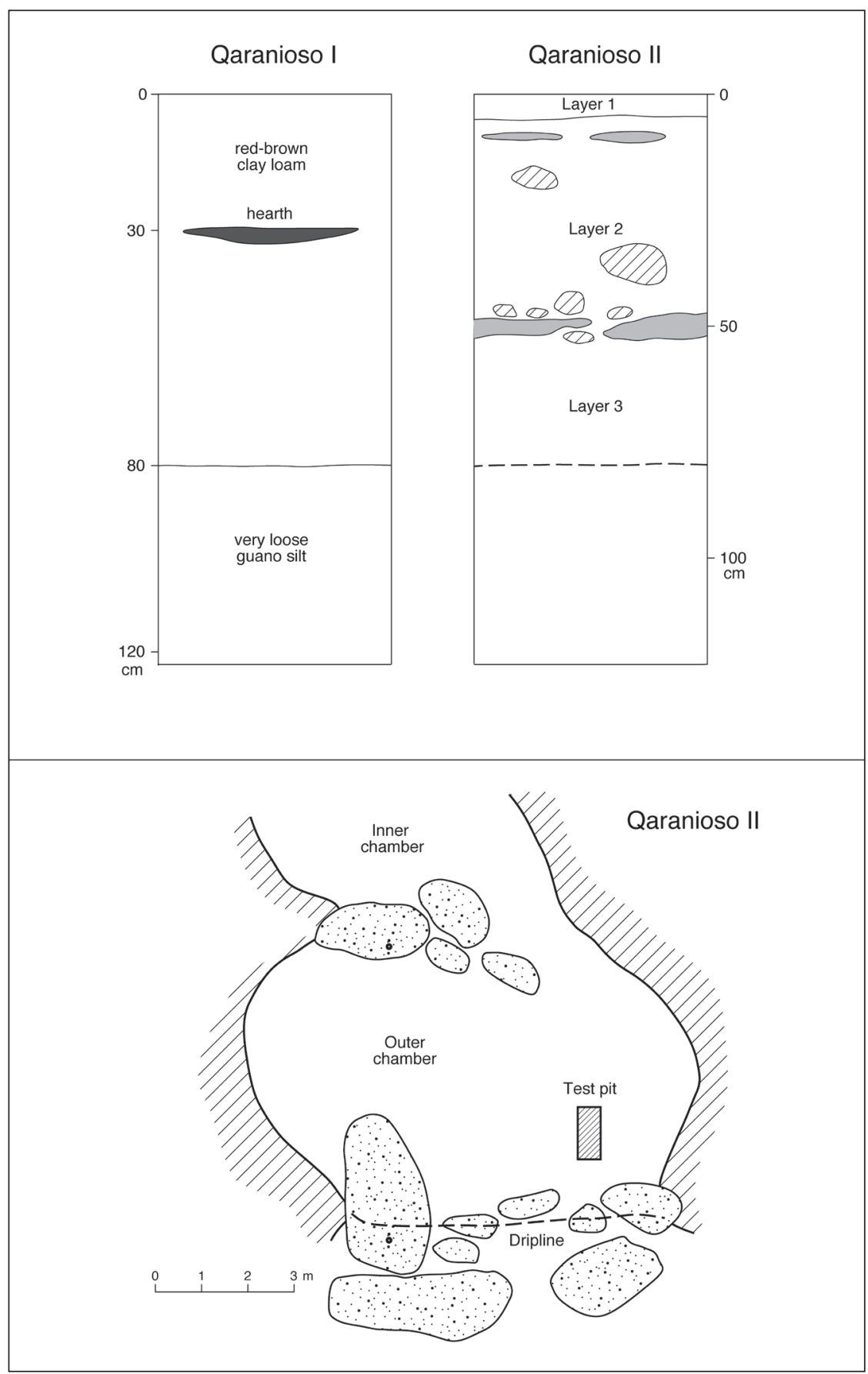

Figure 45. Qaranioso I and II, stratigraphy (I and II) and plan of shelter (II). 
Paddle-relief pottery extended down to Layer 2 and one tooth-impressed sherd, possibly of Lapita age, was recovered from Layer 3. Further excavations were planned for this site in 2000, but were cancelled on account of the political emergency.

\section{Tuvu shelter}

In the middle reaches of the Sigatoka River is Tuvu village and nearby is a shelter, one of several recorded initially by Gifford (1951). The shelter is $14 \mathrm{~m} \times 6 \mathrm{~m}$, with a low rock pile at the entrance, from which it is a step down on to a dry floor scattered with sherds of plain pottery. At the back of the shelter is a low entrance to a second chamber (Figure 46). Several metres inside that a rock wall seals the rest of the cave. It is believed to be a burial chamber. A test pit of $0.8 \mathrm{~m} \times 0.5 \mathrm{~m}$, was excavated in $10 \mathrm{~cm}$ spits and by natural layers, in the centre of the shelter, $1 \mathrm{~m}$ behind the entrance rock pile. This disclosed the following stratigraphy:

Layer 1: $0-10 \mathrm{~cm}$ of grey silt or guano with sherds.

Layer 2: $10-18 \mathrm{~cm}$ depth. Soft, foliated calcite.

Layer 3: $18-52 \mathrm{~cm}$. This is a brown-grey slightly compacted silt and guano layer, with some faint lenses of charcoal and scarce shell and pottery.

Layer 4: From $52 \mathrm{~cm}$ to at least $130 \mathrm{~cm}$ is a soft, orange-brown guano containing no cultural material.

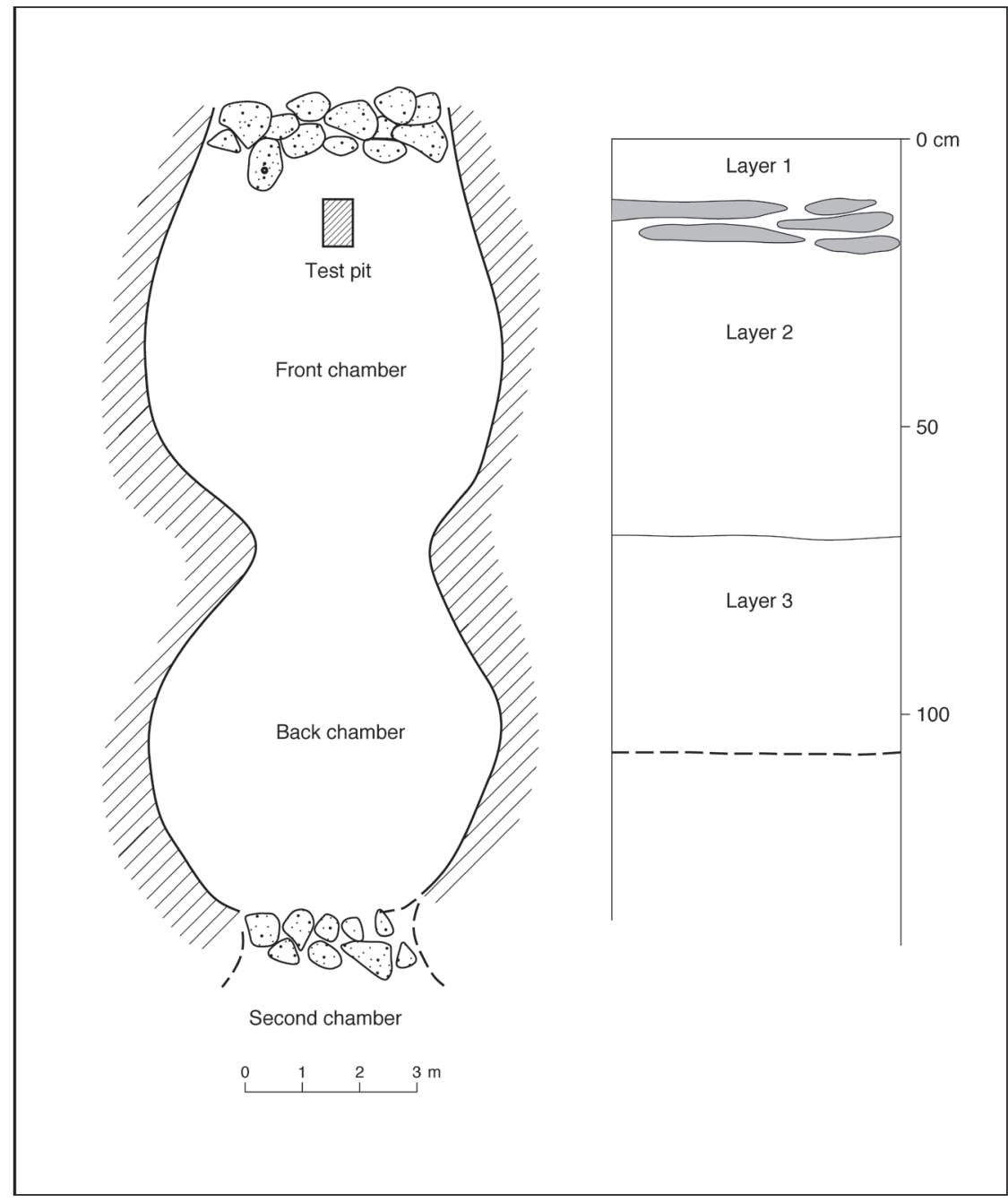

Figure 46. Tuvu, plan of shelter and excavation section. 


\section{Research on data from Karobo VL 18/1}

The site of Karobo was discovered and excavated in the 1960s by the Director of the Fiji Museum, Bruce Palmer. Despite Palmer (1965) making some introductory remarks about the Karobo site, he never subjected the ceramic material to detailed examination nor had the site dated. The VL 18/1 assemblage was, however, frequently mentioned as an important site for understanding the ceramic dimensions of the Navatu phase, as the site was well stratified and contained an intact decorated pottery 'horizon' (Palmer 1965; Golson 1974; Frost 1979). Permission was given in 1997 to re-examine the Karobo material held by the Fiji Museum. The unpublished field notes and illustrations relating to the Karobo excavations were traced to the Auckland Institute and Museum by Professor Roger Green (Department of Anthropology, Auckland University), who copied the material. The following site descriptions derive primarily from those documents.

\section{Location and environs}

The site was located at the eastern end of Karobo beach (Shepherd 1990) on a narrow sand spit/ dune ridge to the east of a small unnamed stream. The site lies $6.5 \mathrm{~km}$ east of the mouth of the Navua River and $1.2 \mathrm{~km}$ west of the Taunovo River (Figure 47). A mangrove swamp lay behind the sand ridge and on its seaward side was a narrow white-sand beach. Small water-cut channels ran through the swamp and bordered the base of the dune. At its highest point the dune ridge was $80 \mathrm{~cm}$ higher than the beach surface and was between $6 \mathrm{~m}$ and $10 \mathrm{~m}$ wide (Figure 48).

Karobo was discovered by Fergus Clunie in late 1963 or early 1964. Clunie collected sherds from a stream-cut channel below the sand ridge and recognised their similarity to leaf and paddle-relief sherds from Sigatoka. Karobo was visited by Bruce Palmer (Fiji Museum), Clunie, Roger Green and others who examined the site and made a collection of the surface ceramics. The site was then surveyed by Les Thompson, Clunie and Palmer. The first excavation, conducted by Palmer, a Fiji Museum worker and local assistants, took place from June 18 to 20, 1964. Palmer and others then excavated from July 1 to 3, and July 15 to 18 . Jack Golson, of the Australian National University, excavated from August 26 to 28 and Thompson surveyed two cross-sections of the site on August 30. Further excavations were conducted from January 28 to

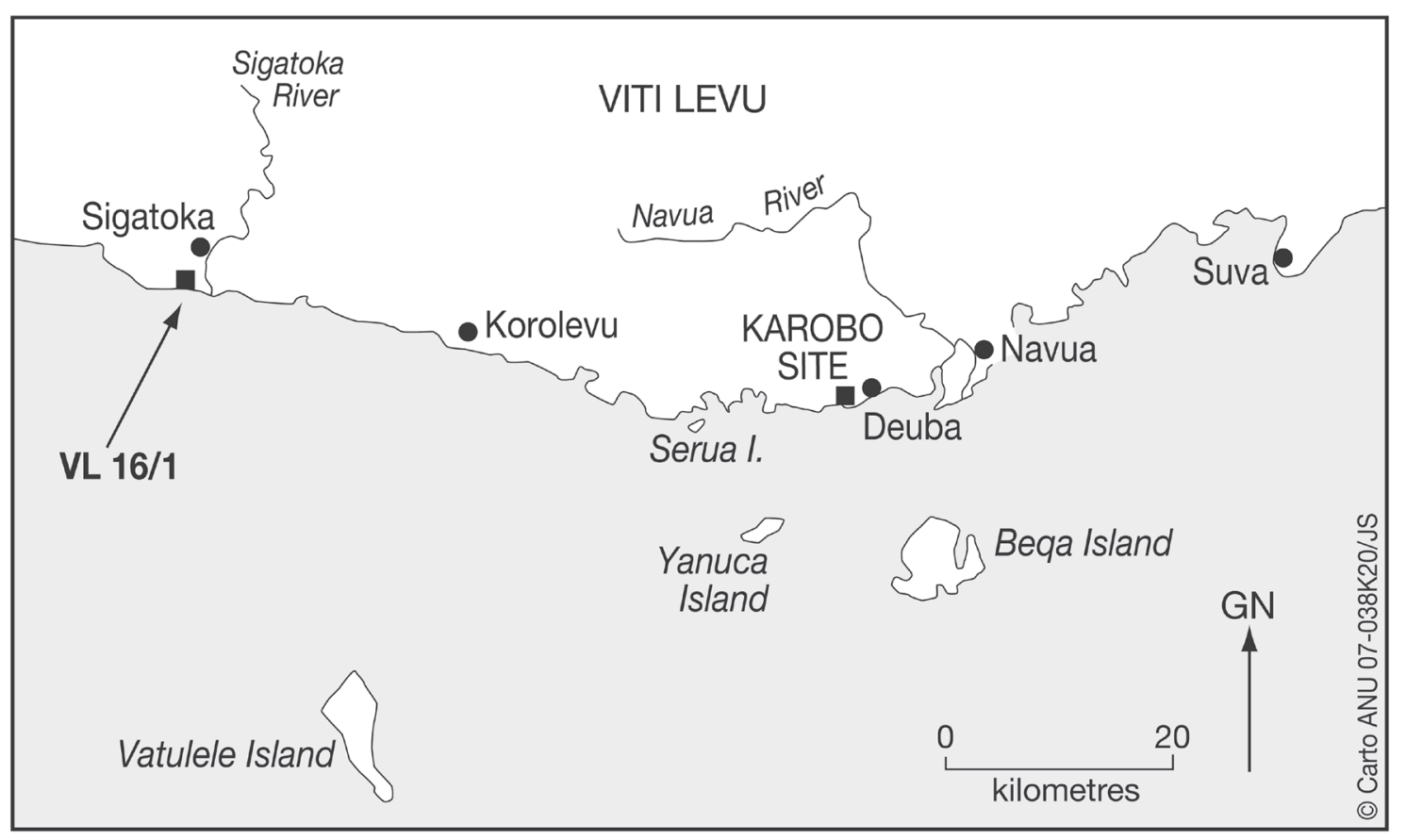

Figure 47. Location of Karobo (VL 18/1) (after Palmer 1965). 


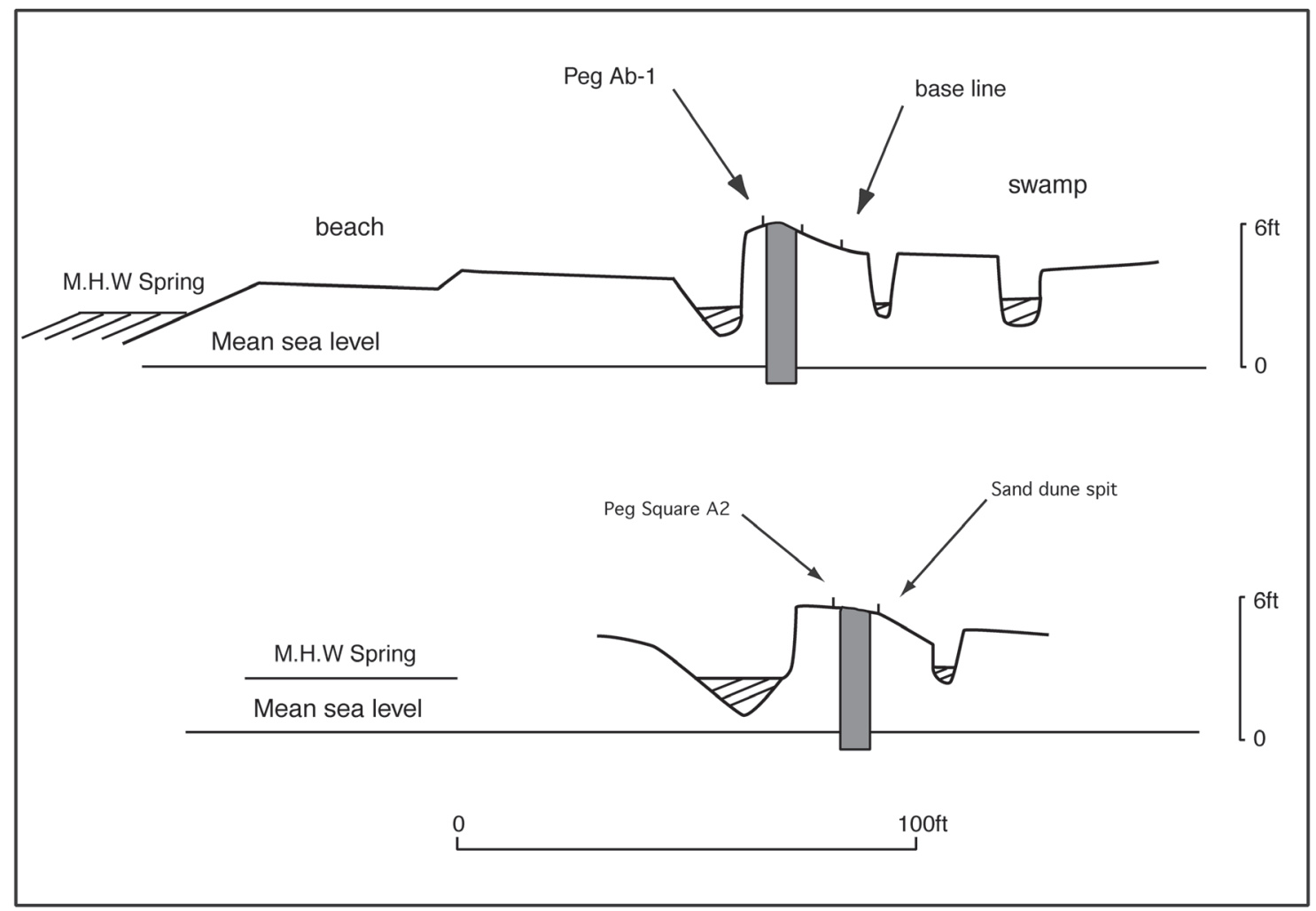

Figure 48. Karobo excavation cross-sections. Redrawn from Thompson 30/08/1964.

31, and February 1 to 8, 1965, with the final excavation taking place from May 16 to 20, 1966. Thus, at least 28 days of excavation are represented by the seven periods of work at Karobo.

A $140 \mathrm{ft}$ baseline running east-west was placed along the landward side of the sand ridge. Squares $10 \mathrm{ft}$ x $10 \mathrm{ft}$ were marked along the grid from east to west using the southeast corner of each square as a reference point. Squares were labelled alphabetically in the north-south plane and numerically in the east-west line. The square with the eastern datum peg was A1, that to its left A2 and the square immediately north of A1 was B1. Squares behind the baseline were identified by lower-case letters. Square Aa-1 was directly south of Square A1 and Square Ab-1 was south of Aa-1. A plan of the site reconstructed from Palmer's description is given in Figure 49. The baseline-square identification system does not appear to have been used in the excavation of Squares X and Y, because if it had they would be located between $73 \mathrm{~m}$ and $76 \mathrm{~m}$ north of the sand ridge. These squares do not appear to have been excavated by Palmer and a report on Square Y makes it clear that these squares were placed on the seaward side of the sand spit, but at an unknown distance east or west of the baseline datum point.

The sand ridge was heavily vegetated and the presence of trees and stumps meant that square excavation was by quadrant, with the southeast quadrant called Quadrant 1 and remaining quadrants numbered clockwise. There was variation in quadrant size. Six-inch baulks were left within each square and each quadrant, leaving a $1 \mathrm{ft}$ baulk between adjoining quadrants. This approach was followed by Palmer and Golson but may not have been adhered to by other excavators.

\section{Methods and stratigraphy}

Excavation was by natural layer using a trowel when cultural remains were dense and by spade when 'non-productive' zones were encountered. Material was sieved (mesh size unknown), or the spoil was examined if the density of archaeological material was low. When the water table was 


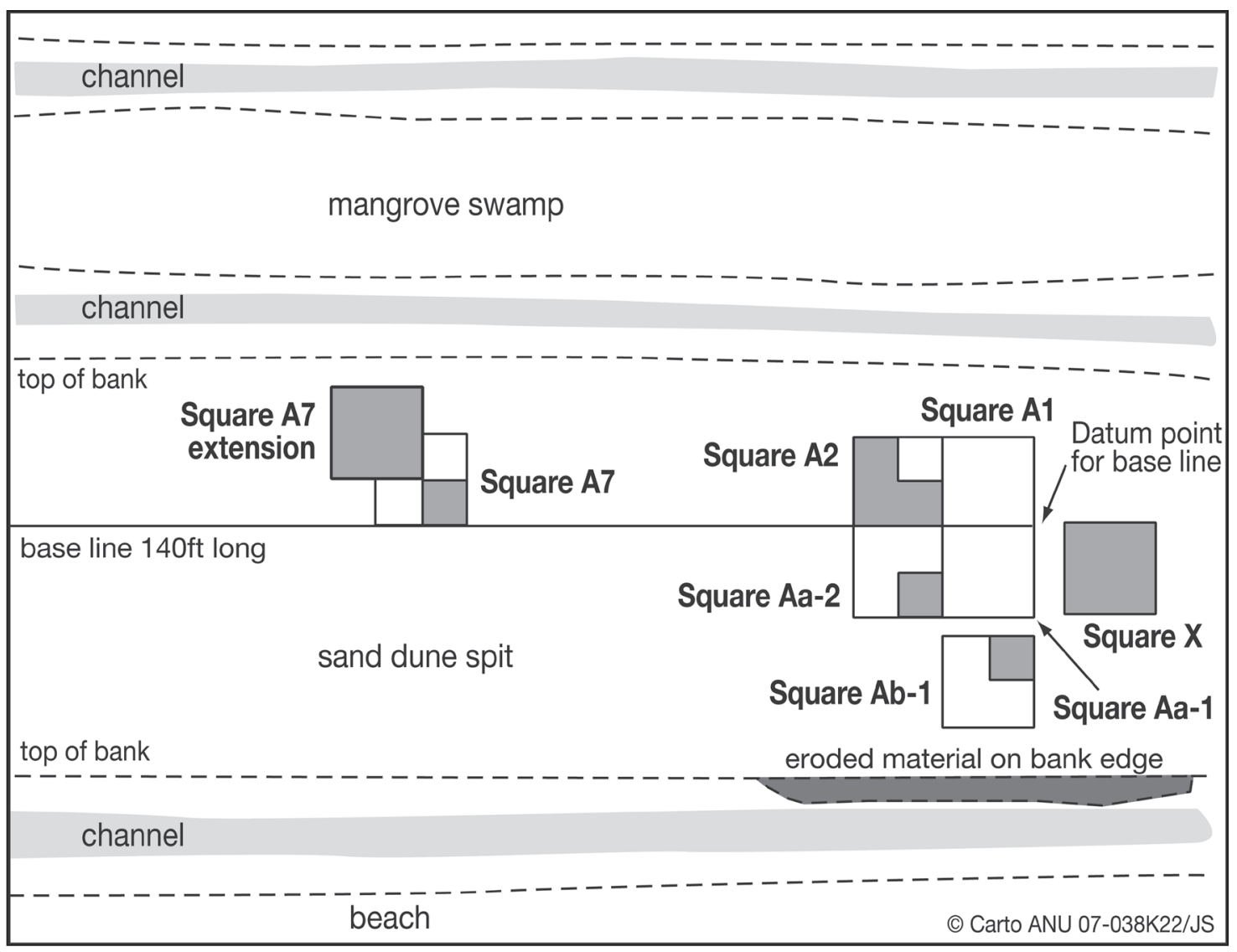

Figure 49. Karobo, plan view of excavated squares (shaded) and environs.

reached, spoil was mounded to form a dam and the matrix removed to the surface for sorting.

The stratigraphy at Karobo consisted of alternating layers of different-coloured sand interspersed in the lower levels by lenses of charcoal and pottery. The stratigraphy of the primary squares is summarised below to provide an overall picture of the deposits across the site. Depth measurements are given in metric units.

Square A2, Quadrants 1 to 3 (Figure 50)

Layer 1: Thin grey-sand humus layer $5-15 \mathrm{~cm}$ deep.

Layer 2: Discontinuous white sand $5-10 \mathrm{~cm}$ in depth. The layer contained small quantities of eroded ceramics, pumice and oven stones.

Layer 3: Compacted brown sand around $60 \mathrm{~cm}$ deep. One Trochus niloticus shell, with small flecks of charcoal, a few pot sherds and pumice.

Layer 4: Yellow-brown damp and compacted sand with rotted pumice, between $10 \mathrm{~cm}$ and $25 \mathrm{~cm}$ thick. This layer lensed out in Quadrant 3 and was thicker in the south of the square.

Layer 5: Grey-brown sand very damp and in its upper $20 \mathrm{~cm}$ mottled with orange-yellow patches. Beneath the mottled material was a clean, grey, very damp sand. Cultural material was abundant at $1.30 \mathrm{~m}$ depth and included fragments of cut wood, seeds, leaves, pottery and charcoal. 
Square A7 (Figure 50)

Layer 1: Thin humus layer with grey sand approximately $5-15 \mathrm{~cm}$ deep.

Layer 2: Clean white sand up to $20 \mathrm{~cm}$ in depth.

Layer 3: Brown sand with abundant humus and many roots. Some pumice but no ceramics or other cultural material. Depth $30-40 \mathrm{~cm}$.

Layer 4: Yellow sand with small flecks of charcoal, pumice and a few ceramic sherds, approximately $30-40 \mathrm{~cm}$ deep.

Layer 5a and b: Grey sand which was lighter in the upper margins (5a) and darker below (5b). Few ceramics or other cultural remains were excavated from this square. Below this were layers described as thin and highly stratified natural deposits.

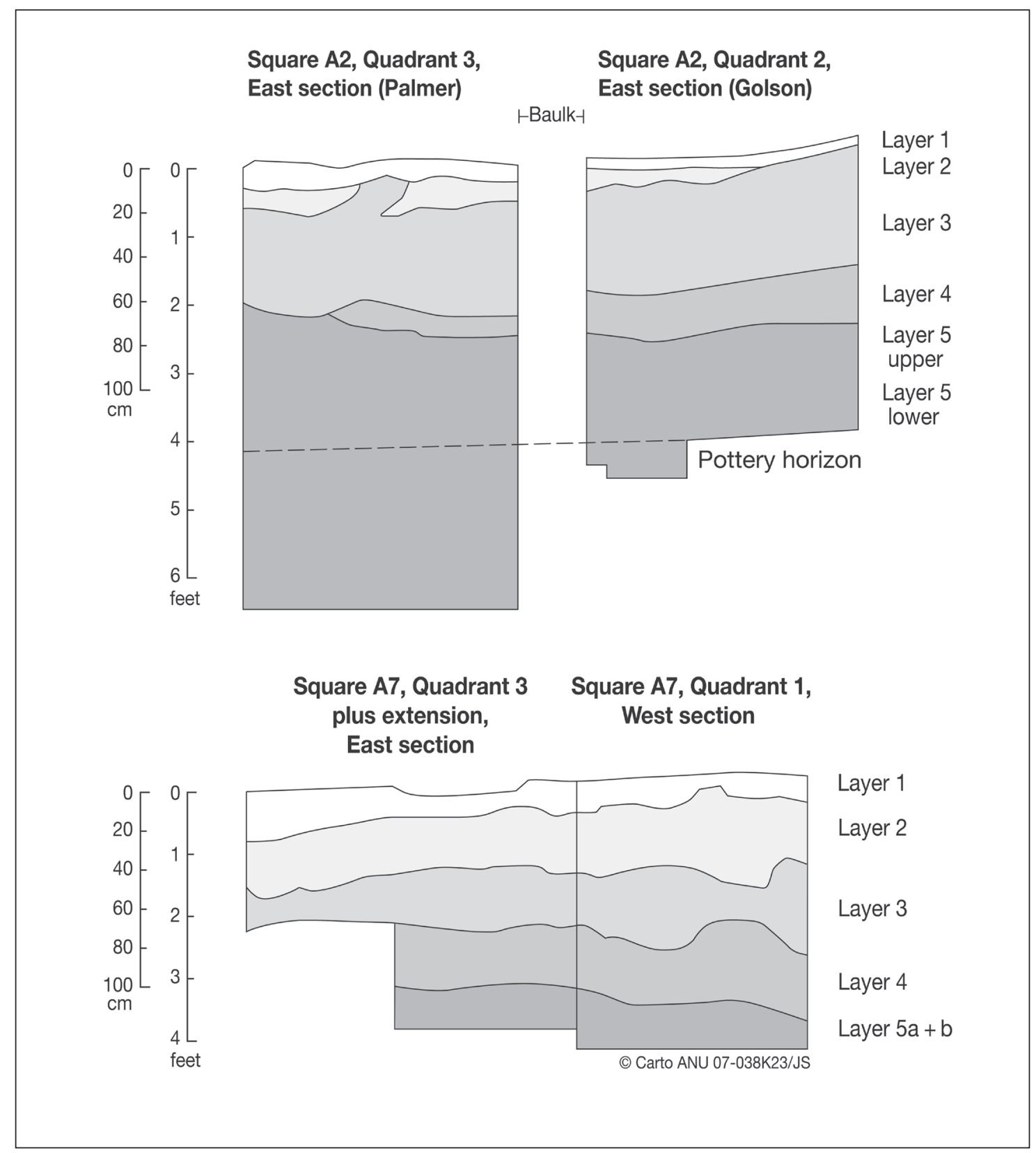

Figure 50. Karobo sections, Squares A2 and A7. 
Squares Aa-2 and Ab-1 (Figure 51)

Layers 1 and 2: As above, but Layer 1 was thinner and Layer 2 thinner and more patchy than comparable layers from Square A2.

Layer 3: Dark-black sand layer with abundant charcoal and roots. Around $20 \mathrm{~cm}$ in depth. The layer contained small quantities of pot sherds, heat-cracked oven stones and pumice.

Layer 4: Dense layer of charcoal which lensed out toward the north of Square Aa-2. Layer thickness was $5-20 \mathrm{~cm}$. No cultural material was recorded from this layer.

Layer 5: Grey-brown stained sand found in patches in Square Ab-1. Not continuous through the squares. In Square Aa-2 patches of Layer 5 intruded into Layer 6 (Figure 51), but in Square Ab-1 the layer was more regular, around 10-20 cm thick.

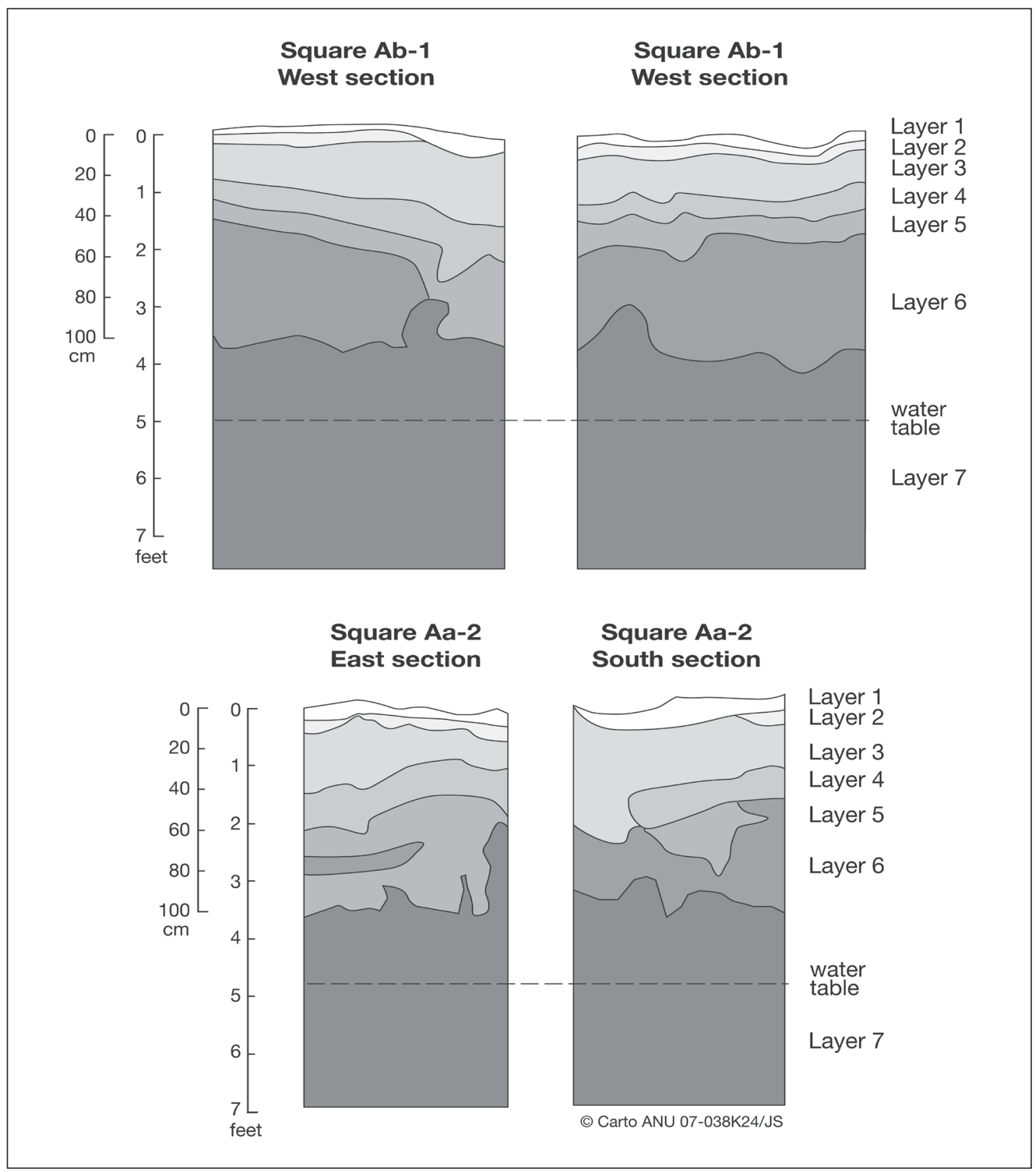

Figure 51. Karobo sections, Squares Ab-1 and Aa-2. 
Layer 6: Yellow-brown sand with pumice, occasional oven stones and ceramic sherds. Towards the bottom of the layer the sand became cleaner and more yellow in colour. This layer was variable in depth, ranging from $10 \mathrm{~cm}$ to $45 \mathrm{~cm}$.

Layer 7: Dark-grey sand mottled in its upper margins with small patches of yellow-brown sand. Below the mottled zone was the wet grey sand in which ceramics, charcoal, seeds and wood were abundant. This layer continued below the water table and was more than $1 \mathrm{~m}$ thick.

\section{Squares $X$ and $Y$}

The stratigraphy of Square X was similar to that of Square A2 where bands of white and yellow sand gave way to a lower layer of grey sand (Layer $5 \mathrm{~b}$ ) at $75 \mathrm{~cm}$ depth. This layer was excavated to $1.7 \mathrm{~m}$ and at the base was the 'pottery horizon' identified by Palmer and Golson in Square A2. Square Y contained four layers; humus layer followed by a clean white beach sand and then a blackish compacted soil with abundant charcoal, oven stones and a few ceramic sherds. Below this was Layer 4 which consisted of a yellow sand with flecks of charcoal and pieces of pumice. Most of the ceramics were found in the upper $15 \mathrm{~cm}$ of Layer 4 and the excavation finished at a depth of $60 \mathrm{~cm}$.

\section{Excavation features}

Features were recorded from Square A2, Quadrants 2 and 3, and Square Y. In Square A2 (Quadrant 3) groups of large sherds belonging to flat-based platters were found at $1.3 \mathrm{~m}$ depth (Layer 5). Under the platter sherds were concentrations of charcoal, ash and large numbers of oven stones. In Quadrant 2 a large log projected from the south wall at the level of the pottery horizon (1.3-1.5 m depth). Remains of oven building and rake out were identified in Square Y in Layer 3 at $25-35 \mathrm{~cm}$ depth.

\section{Site formation and use}

As there is little detailed information available on the Karobo environs and sediments, the following description of site formation is preliminary and requiring further investigation. The earliest in situ occupation level at Karobo appears to be $1.4 \mathrm{~m}$ below the current sand spit/ridge surface, represented by the hearth in Square A2, Quadrant 3. That is, near the top of Layer 5 in Square A2 and the top of Layer 7 in Squares Ab-1 and Aa-2. At this time, the site appears to have been a low beach ridge. Proximity of the cultural deposits to the water table probably results from sediment compaction rather than a post-1600 BP rise in sea level (W. Dickinson, pers. comm., University of Arizona). The geomorphology of Domona Beach just east of Karobo suggests that the past 2000 years witnessed substantial progradation of beach ridges when sediments from the developing Navua/Deuba Delta were transported westwards by the prevailing southwesterly waves. Shepherd (1990:553) dated a log in the Holocene beach ridge deposits of Domona Beach at $1600 \pm 50$ BP (NZ-7554). It seems probable that the prograding coastline at Karobo had, therefore, reached its present position by ca.1600 BP and the Karobo occupation took place on the beach berm. Introduction of fluvial-borne sediments behind the berm led to the development of swamp conditions and expansion of mangrove communities.

No bone and little marine shell was recovered from the Karobo excavations. However, Palmer recorded that a variety of nuts, including Canarium and Pandanus, was present. Most of the botanical remains were found in the lower water-logged layers and Palmer suggested that a cultural origin was probable for the remains, although acknowledging that crabs and water transport of seeds and leaves could introduce some of the smaller fragments. Use of the nuts 
to manufacture coconut oil using the flat-based platters was suggested as a primary activity at Karobo (Palmer 1965). At Sigatoka it has been suggested that similar vessels were used to recover salt through evaporation. However, Golson was far more hesitant about attributing purposeful prehistoric human activity to the nut specimens, noting that in the sump hole excavated into Layer 5 of Quadrant 2, Square A2, shell fragments from two nuts occurred in a crab hole. The low height of the dune spit could also argue against Palmer's suggestion, as both wave action seaward, and flooding and channel cutting landward, could be responsible for the deposition of the wood, nuts and leaves. Nuts are commonly deposited on beaches in Fiji (Smith 1990) and, as Matthews and Gosden (1997) note, care needs to be taken when interpreting botanical remains from archaeological sites. Overall, the prehistoric activities at the Karobo site are not well understood, although cooking, the manufacture of flat-based platters and the preparation of domestic products such as salt or coconut oil are possibilities.

\section{Beqa Island and Ugaga Island}

Beqa Island has an area of 36 sq. $\mathrm{km}$ and it formed from a subaerial stratovolcano about 5 million years ago, while Ugaga Island is a small volcanic island about $0.25 \mathrm{~km}^{2}$ located 3.5 $\mathrm{km}$ southwest of Beqa within the 390 sq. $\mathrm{km}$ Beqa lagoon (Figure 52). Beqa is high enough to create a marked orographic effect with more rainfall (about $300 \mathrm{~cm}$ annually) on the windward or southeastern side than the leeward side (Rajotte and Bigay 1981). Kulu Bay is situated on the southwest coast of Beqa Island and faces southwest towards Ugaga Island, $3.5 \mathrm{~km}$ distant. Dentate-stamped sherds were among a small surface collection of 141 sherds collected by Crosby (1988) and the location was given the code BQ175A.

Kulu Bay 1

Sherds, including some of Lapita type, are scattered on the surface approximately $65 \mathrm{~m}$ directly inland from the HTM in the middle of the bay (Figure 52). They lie in a shallow swale between two low ridges which lie more or less parallel to the beach front. The seaward ridge is of sand, but the inland ridge is of unsorted boulders and soil. It is an irregular feature sloping gently back into the forest floor inland and is probably an old stream bank. In any event, it is apparent that water moves periodically down the swale. A $3.0 \mathrm{sq}$. m excavation was set out in the swale in an area where some dentate-stamped sherds were recovered. The stratigraphy was as follows:

Layer 1: 0-25 cm of stiff, blocky, chocolate-brown clay loam, containing sherds and scarce shell. It was probably a garden soil.

Layer 2: From $25 \mathrm{~cm}$ to $110-130 \mathrm{~cm}$ in square C11. The matrix is of stiff, exceptionally sticky, dark-brown clay and shell hash, with some shell midden. The layer is increasingly wet with depth. Below 50-60 cm there is an increase in the quantity of bone, especially of fish bone. Chert, quartz and basalt flakes occur throughout and pottery is common. The latter is mostly plainware but it includes dentate and paddle-impressed wares, mixed together.

Layer 3: From $110 \mathrm{~cm}$ to $130-160 \mathrm{~cm}$ in square $\mathrm{C} 11$. The matrix is the same stiff, exceptionally sticky, dark-brown clay. It has no shell hash, but a few thin lenses of yellow carbonate sand near the bottom. Large shells of Turbo and other taxa are more conspicuous. Bone is both relatively more abundant than above and in greater diversity, including bird bone. The same pottery and lithics as above occurred in conjunction with candlenut and other woody fragments. 
Layer 4: This is a beach deposit at $160 \mathrm{~cm}+$ (excavated to $170 \mathrm{~cm}$ and probed to at least $0.5 \mathrm{~m}$ below that) of blue-grey coarse sand and shell grit, with broken shell and coral pieces in clasts up to $10 \mathrm{~cm}$ long.

Throughout the stratigraphy there is abundant evidence of crab-hole disturbance, which might account for the mixing of pottery types. The water table occurs at about $1.1 \mathrm{~m}$ and is probably responsible for acidic conditions in which the shell hash of Layer 2 has disappeared in Layer 3, leaving only the larger shells. The absence of any features, the relative scarcity of charcoal, and an impression of a broad homogeneity in the material from top to bottom suggests this is a transported site. It has either (or both) been washed down the swale from further inland - although there was no surface indication of that upstream in the swale; or deposited by storm surge. The mixing of substantial quantities of shell hash with clay might indicate the latter mechanism.

The first square excavated was $\mathrm{C} 10$, which was taken out in $0.2 \mathrm{~m}$ spits down to $0.6 \mathrm{~m}$. When the nature of the material was apparent, and despite the difficulties of doing so, the remainder of the excavation was in $10 \mathrm{~cm}$ spits. Material was bucketed down to the beach and washed in sea water. The stiff, exceptionally sticky clay would not wash through any sieve, even with considerable effort. It had a toffee-like consistency and for the most part it was pulled into small pieces over the sieves, to extract the larger pieces of pottery and midden, the residue then being rubbed through $4 \mathrm{~mm}$, and in bone-rich areas, $2 \mathrm{~mm}$, sieves. Inevitably, this led to some

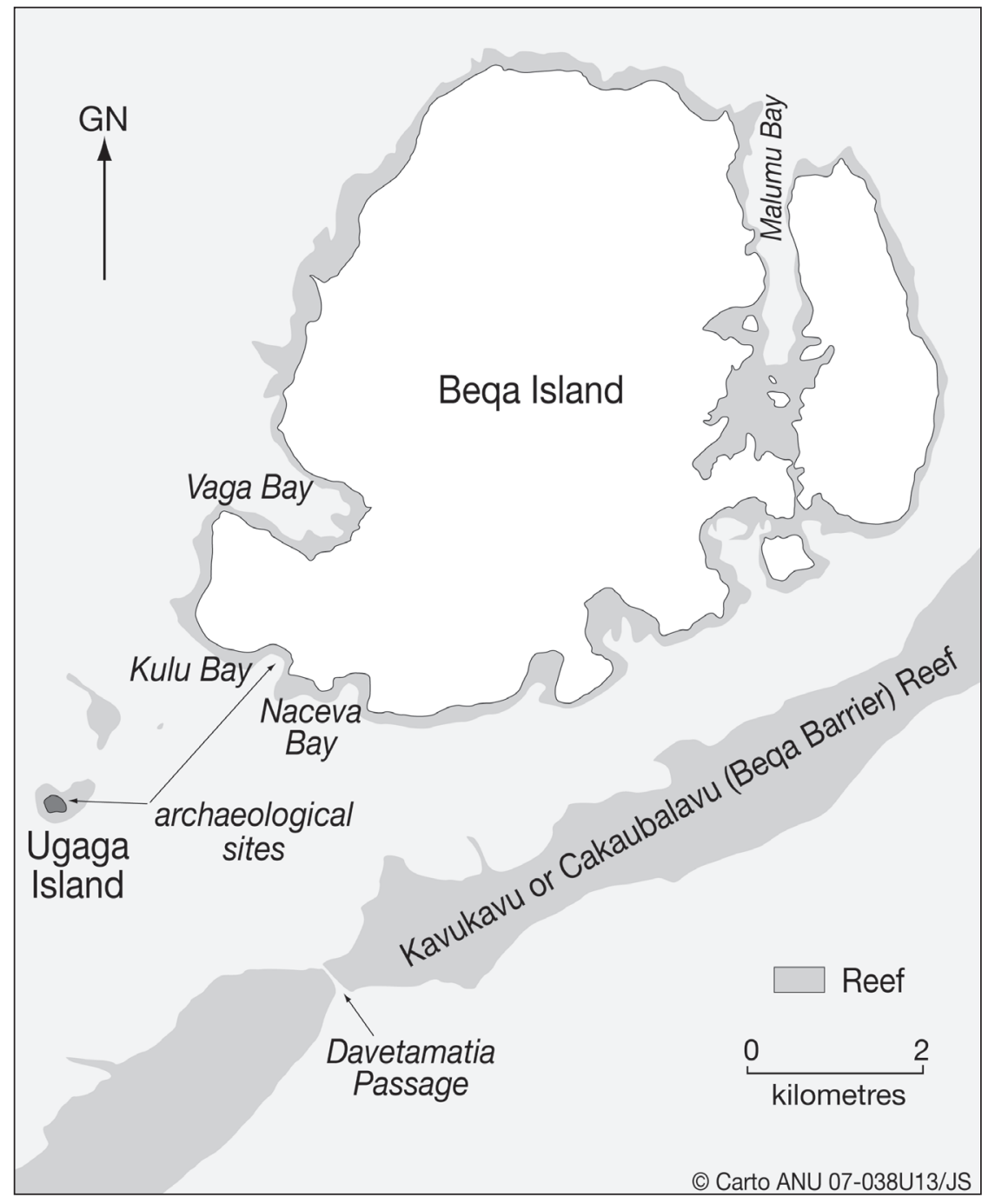

Figure 52. Location of Ugaga Island and Kulu Bay. 
damage to the material, and while the site is quite rich it was decided not to excavate below $1 \mathrm{~m}$ in $\mathrm{C} 9$ and $\mathrm{C} 10$, nor to open any additional squares until some means of dealing with the stickiness of the matrix could be found. Subsequent enquiries were not encouraging, since the usual de-flocculating chemicals cannot be used safely, in environmental terms, at the industrial levels required.

\section{Kulu Bay 2}

Halfway between site 1 and the beach is Kulu 2. It was located not because of any surface evidence but to test the seaward extent of the Kulu 1 stratigraphy. In fact, excavation encountered two bundle burials, of one larger and one smaller adult individual, only $20 \mathrm{~cm}$ below the surface. There was some paddle-impressed sherds in the vicinity, but not obviously associated with the burials. The latter were exposed and photographed, then reburied in the same place. Our workers from Naceva village, in the next bay, conducted a brief service and set a margin of stones and a headstone at the grave. The stratigraphy of Kulu 2 shows that yellow beach sand extends for at least a metre below a $20 \mathrm{~cm}$ topsoil of sandy brown loam.

\section{Ugaga Island}

Ugaga Island is located $3.5 \mathrm{~km}$ southwest of Naceva Bay on Beqa Island (Figure 52). The island is about $150-200 \mathrm{~m}$ in diameter and surrounded by a fringing reef. It has small beaches on the southern, northern and western sides, but only the northern beach, which is sheltered from the prevailing southeast trade winds, is of any extent. The island is composed of augite-olivine basalt breccia of early Pliocene age (Band 1968; Whelan et al. 1985). The main ridge of this material runs east-west and reaches an elevation of $20 \mathrm{~m}$ above sea level. There is no permanent freshwater source on the island. A small sand plain below the volcanic ridge, with an area approximately $30 \mathrm{~m} \times 35 \mathrm{~m}$ contains archaeological deposits. To its north, the sand plain has been eroded by wave action and forms a terrace edge which is $1.5-2.0 \mathrm{~m}$ above the high-tide water level. Outlier coconut palms 2-4 $\mathrm{m}$ from the terrace edge indicate recent storm erosion. The beach zone is $20-28 \mathrm{~m}$ wide at low tide. Behind the beach terrace, the sand plain is bordered by soil and rock-covered slopes (Figure 53). Vegetation consists of numerous economic introductions, including coconut, pandanus, banana, breadfruit and lemon trees and grasses (e.g. Panim and Pennisteum). No root crops were observed on the island in 1997.

Ugaga Island was given to the Vunivalu of Serua, as payment for defending Naceva village against attack from Rukua around 1830. Food crops planted on the island by the people of Naceva were said to have been taken to Serua. In 1997, links with Serua were still strong but there was some uncertainty over the ownership of Ugaga Island, with the Vunivalu of Serua, Naceva village and the Lawaki Mataqali all having some claim. In practice, permission to visit the island is sought through Naceva village. Fishing rights around Ugaga Island are jointly held by villagers from Sawau, Rukua, Naceva and Yanuca Island. The prehistoric site on Ugaga Island was first recorded by Andrew Crosby, then a student at Auckland University, in the mid-1980s (Crosby 1988). Two sites on the northern beach edge were identified (UG 1 and UG 2) and estimated as covering 1500 sq. m. Pottery sherds were obtained from a thin charcoal-stained surface layer $150 \mathrm{~mm}$ in depth. Between $46 \%$ and $52 \%$ of the recovered sherds were decorated. Heavy impressed 'ribs', parallel ribs, chevron ribs and cross-hatch-impressed sherds were abundant. Rims were mostly expanded but some sharply everted rims were found. Crosby (1988:115) concluded from the ceramic collection that Ugaga was likely to be a single-phase site that recorded the transition from the Sigatoka to the Navatu phase (2200-1800 BP). Further, there was the possibility that Ugaga was undisturbed and therefore provided an ' . . opportunity to gain a full areal record of site layout from this poorly understood period of Fiji's prehistory' (Crosby 1988:223). 
An initial walk-over survey of the island suggested the main archaeological deposits were located on the sand plain behind the northern beach edge. Ceramics and shell fragments were eroding along the terrace edge from the eastern edge of the beach to a distance $35 \mathrm{~m}$ west of that position. The first excavation was a $1 \mathrm{mx} 1 \mathrm{~m}$ square called Test Pit 1 , located to test the area immediately behind the daily camp site and north of a water tank built in 1992 (Figure 53). Although a post hole and a large Tridacna maxima shell were found in Test Pit 1, the ceramics were few, fragmentary and eroded.

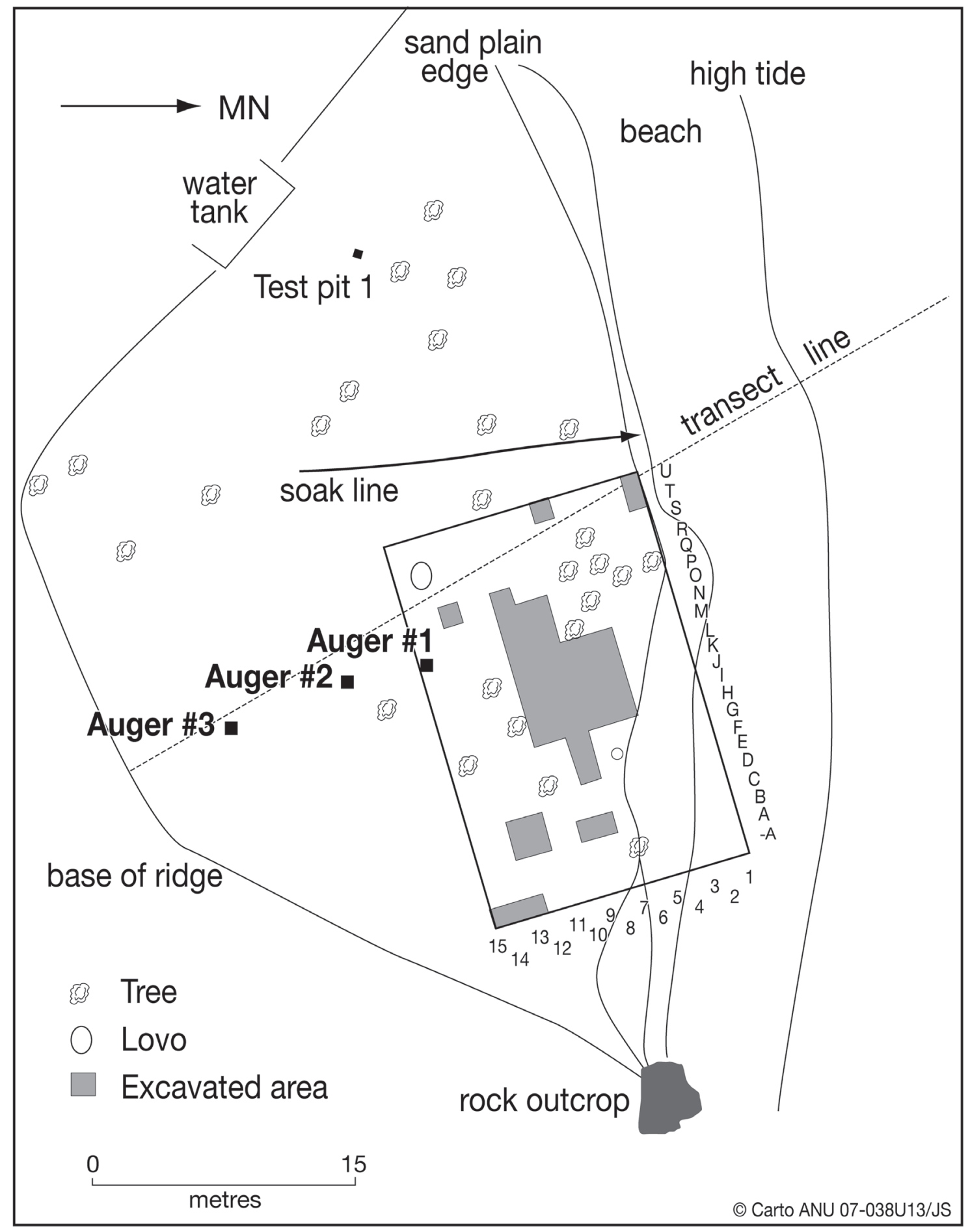

Figure 53. Ugaga Island, plan view of excavated area and environs. 
Attention then focused on the eroding material exposed along the terrace-beach edge and a $1 \mathrm{~m} \times 2 \mathrm{~m}$ rectangle (T/U-1) was excavated to determine the nature of the terrace-edge deposits. The excavation showed that ceramic sherds, marine shells and specks of charcoal were located to a depth of $60 \mathrm{~cm}$. However, the major concentration of cultural material lay between $30 \mathrm{~cm}$ and $40 \mathrm{~cm}$. To examine the sand-plain deposits excavation squares were positioned on a reference grid. The east-west baseline was labelled -A to $\mathrm{Z}$ and the north-south line labelled numerically from 1 to 15, with Square 1 the northernmost point. Thus, each $1 \mathrm{~m}$ square (except Test Pit 1) had an alphabetical and numerical code describing its location on the sand plain (Figure 53).

A total of 57 sq. $\mathrm{m}$ was excavated, with a main area comprising 43 sq. m providing a central sample of the sand-plain deposits (Figure 54). Eastern excavations outside the main area consisted of squares C/D12-13 (2 m x $2 \mathrm{~m}),-A 13-15(1 \mathrm{~m} \times 3 \mathrm{~m})$ and C8-9 (1 $\mathrm{m} \times 2 \mathrm{~m})$. Western excavations were T/U-1 (1 m x $2 \mathrm{~m})$, U6 (1 m x $1 \mathrm{~m}), \mathrm{Q} 13$ (1 $\mathrm{m} \times 1 \mathrm{~m})$ and Test Pit $1(1 \mathrm{~m} \times 1 \mathrm{~m})$.

Material was extracted in $10 \mathrm{~cm}$ spits and by natural layer using trowels and sieved through $3 \mathrm{~mm}$ and $6 \mathrm{~mm}$ mesh. Cultural material (marine shell, pottery, bone and charcoal) was retained for further analysis from the surface to $50 \mathrm{~cm}$ depth. At the end of the excavation a final 50-60 cm spit was sieved to ensure basal deposits had been reached. In addition, Squares C/D12-13 were excavated down to $80 \mathrm{~cm}$, and Squares -A13 to -A15, Q13, U6 and C8, I8 and L8 were taken down to $70 \mathrm{~cm}$.

\section{Stratigraphy}

The stratigraphy of Ugaga Island was relatively simple, consisting of an upper layer containing the majority of the prehistoric material and three lower layers where cultural remains were sparse or absent. The two upper-layer descriptions were determined from the excavations, while the stratigraphy of the lower layers was identified by test pits and augering (Figures 55-57).

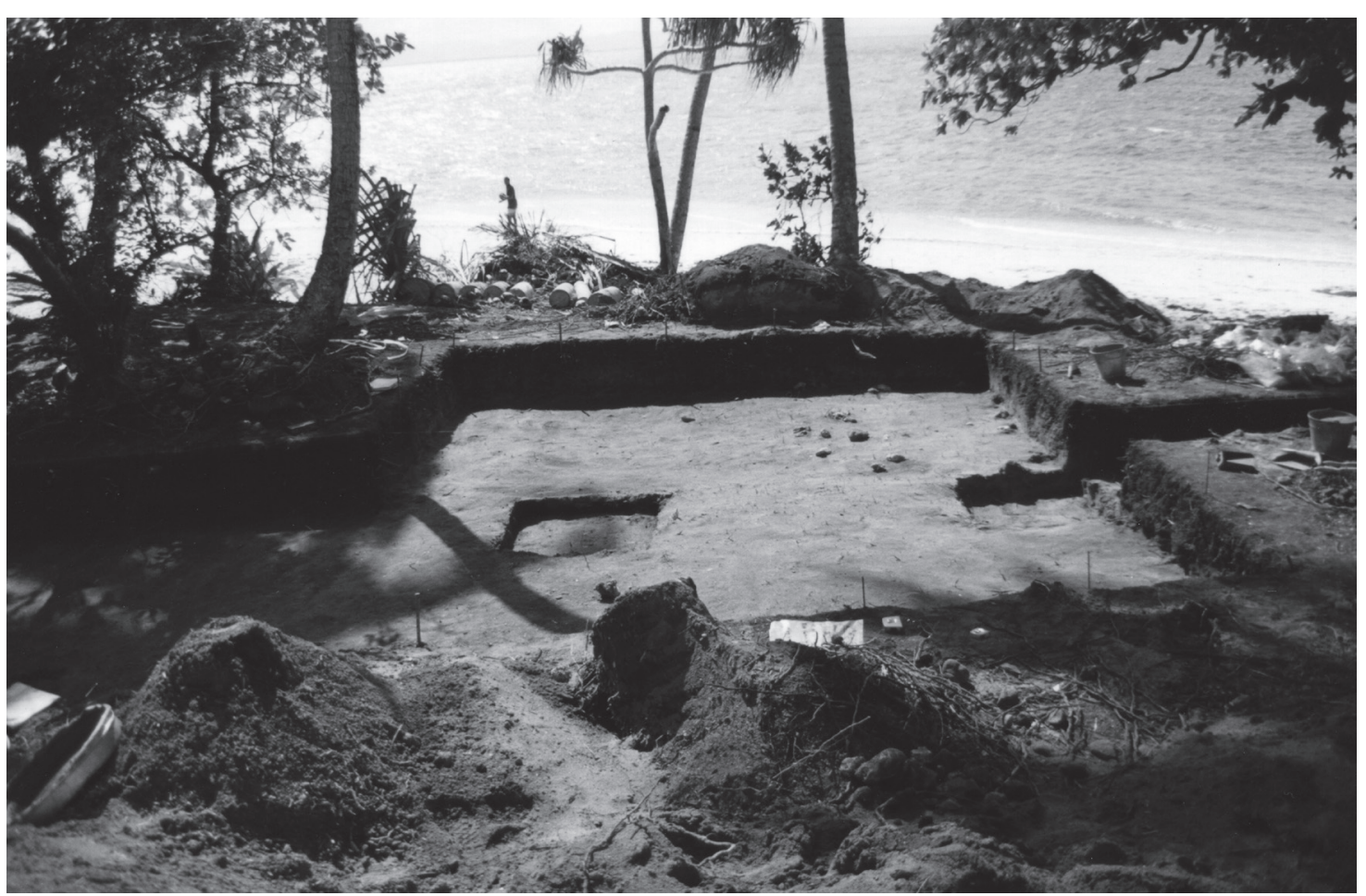

Figure 54. Ugaga Island, view of excavated area. 
Layer 1: Was the principal cultural layer of the site. It consisted of a brownish-black silty clay with variable amounts of sand, abundant whole and fragmented marine shells, ceramics, oven stones and coral. The colour ranged from 7.5YR $2 / 2$ near the surface to $10 \mathrm{YR} 2 / 2$ at $40 \mathrm{~cm}$ depth, where it was a very dark-brown silty clay. Layer $1 \mathrm{pH}$ levels showed little variation ( $\mathrm{pH} 6.75$ to 7.0 ) over the site. Layer 1 was generally around $30-40 \mathrm{~cm}$ in depth and had been disturbed by root penetration from surrounding coconut palms and earthoven construction. After shellfish remains, ceramics were the most abundant evidence of prehistoric activity. Sherds decorated with dentate stamping, lip notching and different types of paddle relief were found throughout the Layer 1 deposit. Charcoal was relatively common in this layer with individual fragments of more than $100 \mathrm{~g}$. Hermit crabs using the shells of Nerita sp. were abundant along the beach edge zone and frequently burrowed into Layer 1, illustrating their potential for site mixing by turning over deposits and introducing non-midden shell into a site. Two fragments of bottle glass (T/U-1), a piece of ceramic plate (K7), a metal bottle cap and a roofing nail (C13) were found in the top spit.

In the eastern part of the site (-A13-15, C/D12-13) a thin lens underlaid Layer 1.

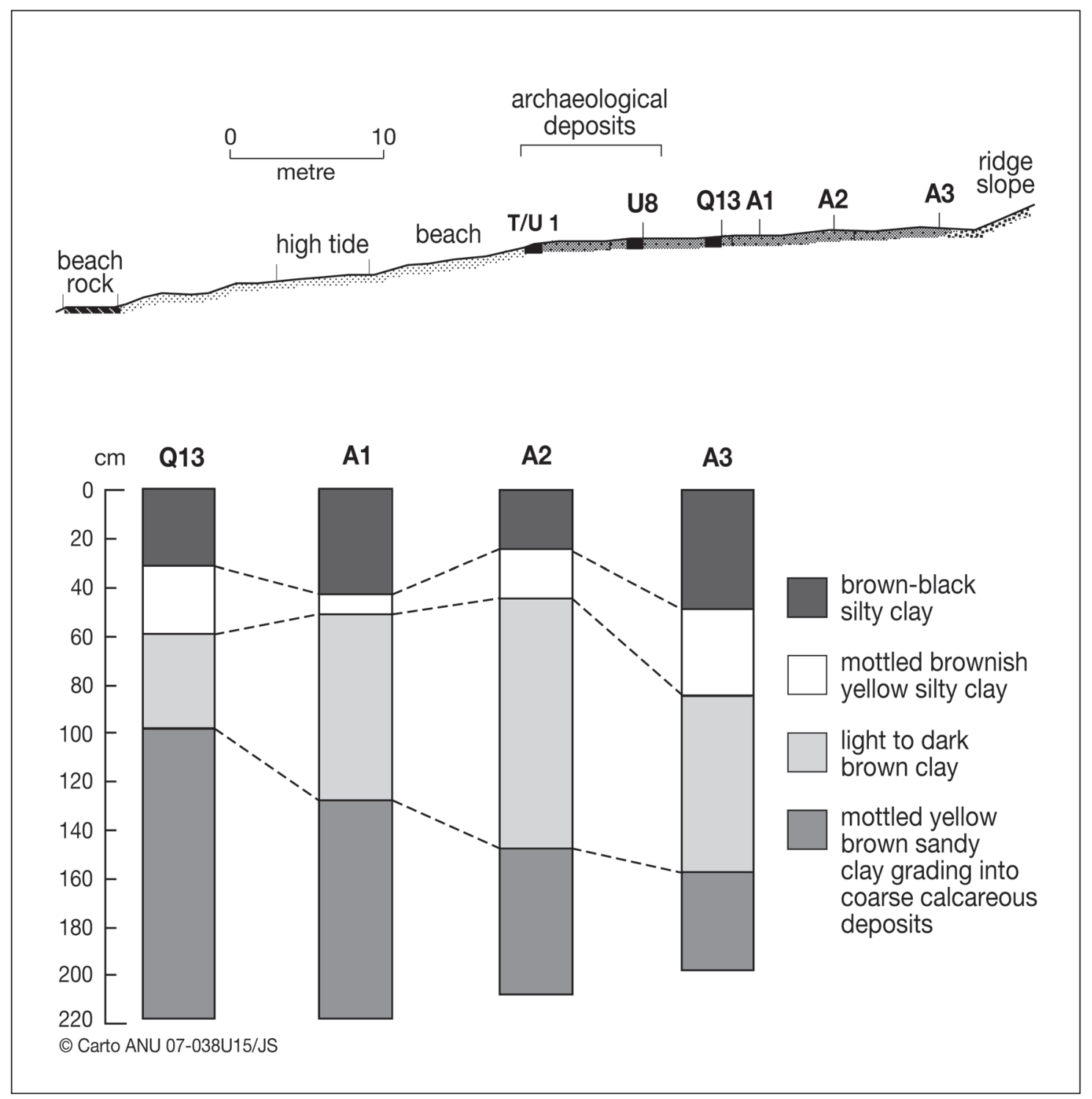

Figure 55. Ugaga Island, stratigraphy of auger transect. 


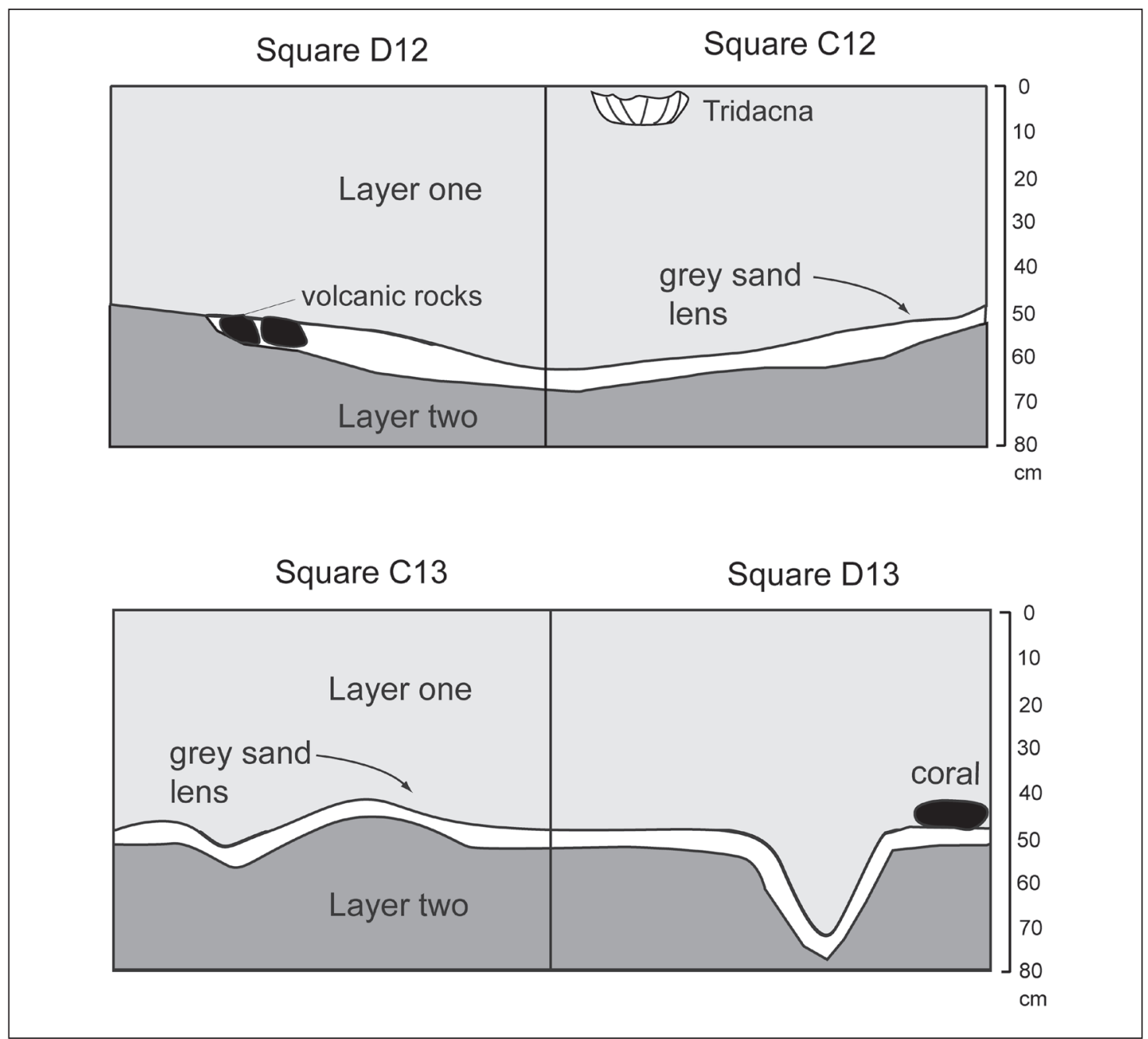

Figure 56. Ugaga Island, stratigraphy of CD12 (north) and CD13 (south).

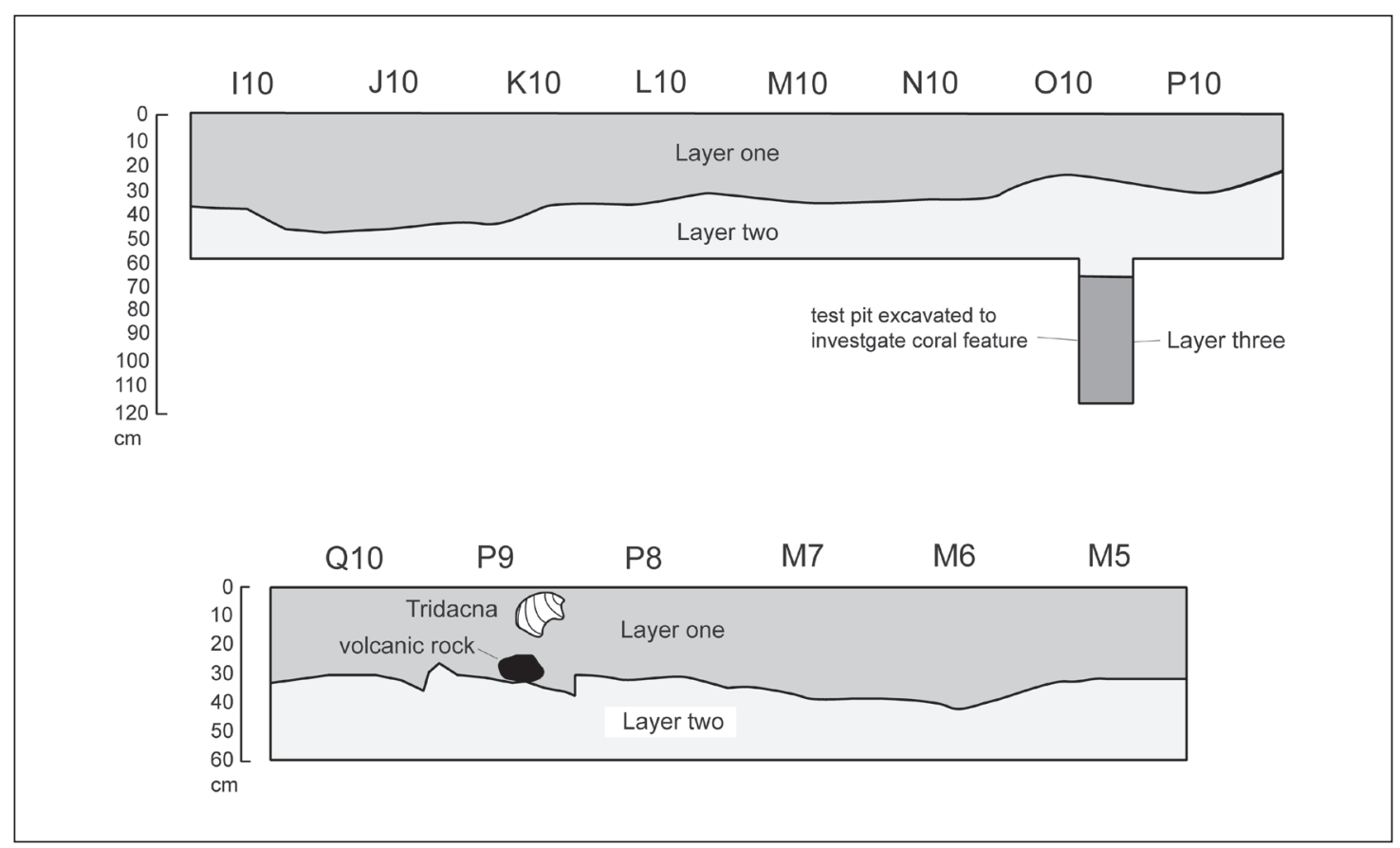

Figure 57. Ugaga Island, stratigraphy of Squares 110 to P10 (south) and Q10, P9-8, M7-5 (west). 
It consisted of a mottled dark-greyish silty sand (10YR 4/2, $\mathrm{pH}=7.0)$ that contained a few plain pot sherds and marine shellfish (Figure 56).

Layer 2: A mottled brownish-yellow silty clay (10YR 4/4, $\mathrm{pH}=7.0$ ) that was mixed with coarse calcareous grains. Along the terrace edge this layer contained a greater proportion of sand, but south and west of the edge the clay content increased, making the deposits wet and sticky. Layer depth was variable from $6 \mathrm{~cm}$ to $21 \mathrm{~cm}$. The difference in layer depth over the site was probably due to cultural activities (i.e. oven building), the amount of vegetation disturbance, and the proximity to colluvium transported from adjacent slopes. Ceramics from squares with high clay contents were weathered, particularly those with shell temper. However, there was little cultural material in this layer, most of which was found at the interface between Layers 1 and 2. Charcoal existed as small and dispersed flecks.

Layer 3: Was differentiated from Layer 2 by the increasing quantity of clay. The colour of this layer ranged from light yellow-brown to dark-brown (10YR 4/4 to 7.5YR 4/4, pH=7.0). Calcareous sand and small nodules of rotted pumice and coral occurred throughout this layer. No cultural material was identified in the auger-hole spoil or in test pits dug into the layer from excavated squares. Layer depth in the auger holes varied from $37 \mathrm{~cm}$ to $100 \mathrm{~cm}$. This layer was prominent to the south and west of the site but was difficult to distinguish towards the front of the site.

Layer 4: Consisted of a mottled brownish-yellow sandy clay (10 YR 6/6, $\mathrm{pH}=7.0)$ that became wetter as depth increased. In the lower part of the layer the silty-clay content decreased, grading into a coarse grit of shell and coral fragments. Large blocks of coral were found towards the base of Layer 4 and the water table was reached at $2.5 \mathrm{~m}$ depth (Figure 55).

Features were apparent across the site, the majority consisting of concentrations of fire-cracked rocks (Figures 58-59). Large quantities of charcoal near some of these stone concentrations indicated that many represented the remains of oven building and rake out. These features were mostly found between the surface and $30 \mathrm{~cm}$ depth. Throughout the deposits shellfish remains were prominent. Clusters of Trochus niloticus shells were found in Square C12 and five Tridacna maxima shells in Square O9 (Figures 58-59).

An oval-shaped group of coral cobbles was found on the surface of Layer 2 in Square P10 (Figure 59). The cobbles ranged in size from $12 \mathrm{~cm}$ to $27 \mathrm{~cm}$. A test pit was dug through the feature to $120 \mathrm{~cm}$ but the feature did not extend below $45 \mathrm{~cm}$ depth. This feature most likely represents the base of an oven, an interpretation backed up by other findings in Fiji and the Pacific. For example, Best (1984:74) records the ethnographic use of coral ovens in sennit (magimagi) manufacture. Coral heating stones are also known from New Caledonia, Reef/Santa Cruz and the Talepakemalai site on Mussau (Kirch 1997:213; Spriggs 1997:136).

The edge of a large $2.0 \mathrm{~m}$ diameter oven was identified in Squares -A13/-A14 The oven deposits consisted of a dark charcoal-stained sand and numerous fragments of burnt shell (Figure 58).

The basal deposits at Ugaga are calcareous and form a low ridge parallel to the beach terrace near the front of the site. The Layer 4 beach material was probably laid down during a period of higher and relatively stabilised sea level from 6000 to 4000-3000 BP. During this time lateral shoreline erosion was significant and closure of what Nunn (1990:351) terms the 'Holocene high energy window' occurred after coral reefs had reached sea level and reef flats had developed. 
Sea level fell by about $0.6 \mathrm{~m}$ (Shepherd 1990) from 3000 BP to the present. Nunn (1990) suggests a maximum Holocene sea level of 1-2 $\mathrm{m}$ above present sea level. Behind the low ridge, silty clays from the hill slopes overlay, and to a certain extent became integrated with, the Layer 4 deposits. The original surface when people first arrived on Ugaga probably varied from a relatively clean silty sand to the east, to a compact silty clay with calcareous inclusions in the west. Although on a smaller scale, the processes outlined above for Ugaga Island have also been noted at other prehistoric sites in the Pacific (Kirch and Hunt 1997).

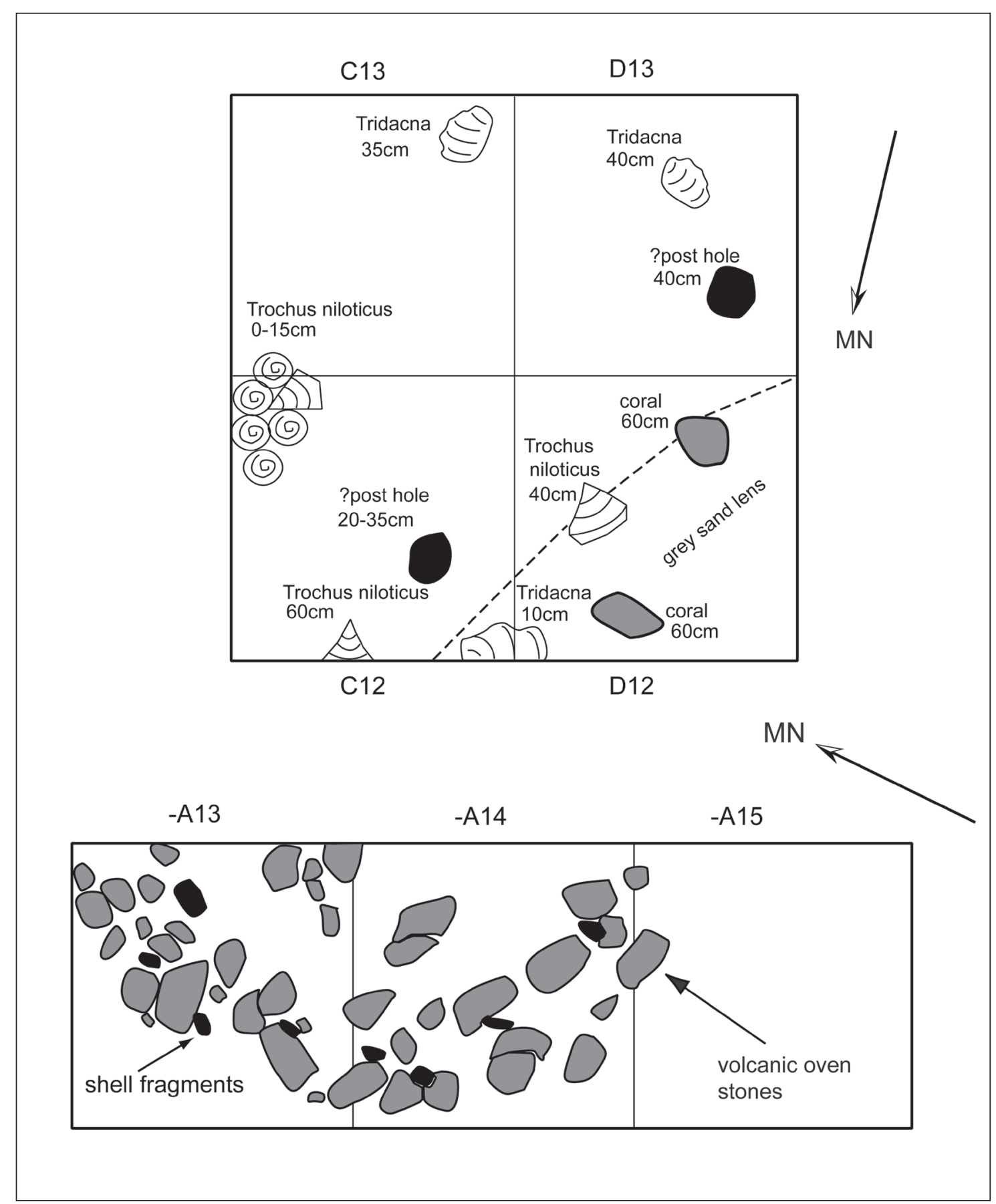

Figure 58. Ugaga Island, plan view of features in CD 12-13 (top) and -A13-15. 


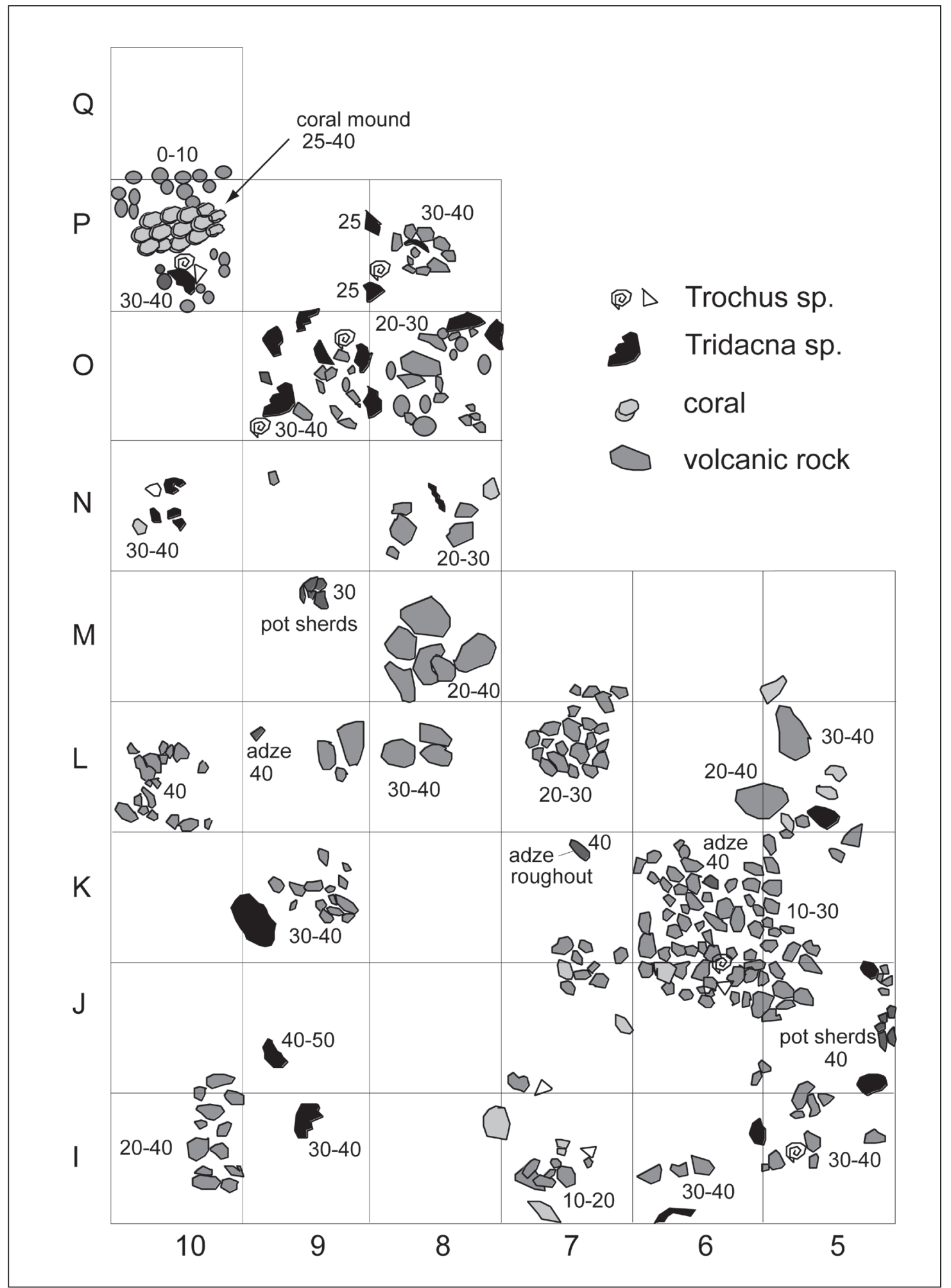

Figure 59. Ugaga Island, plan view of features exposed in main excavation area. Depths are spot heights below ground surface in $\mathrm{cm}$. 


\section{References}

Anderson, A., Clark, G. and Worthy, T. 2000. An inland Lapita site in Fiji. Journal of the Polynesian Society 109: 311-316.

Anderson, A., Roberts, R., Dickinson, W., Clark, G., Burley, D., De Biran, A., Hope, G. and Nunn, P. 2006. Times of sand: Sedimentary history and archaeology at the Sigatoka Dunes, Fiji. Geoarchaeology 21: 131-154.

Band, R.B. 1968. The geology of southern Viti Levu and Mbengga. Geological Survey of Fiji, Bulletin No. 15.

Best, S. 1984. Lakeba: The prehistory of a Fijian island. Unpublished PhD thesis, Department of Anthropology, University of Auckland.

Best, S.B. 1987a. A preliminary report on the Sigatoka burials. Domodomo 3: 2-15.

Best, S.B. 1987b. Sigatoka dune burials Site VL 16/1. A preliminary report. Unpublished report, Anthropology Department, University of Auckland.

Best, S.B. 1989. The Sigatoka dune burials Site VL 16/1. Unpublished report to the Fiji Museum, Suva.

Birks, L. 1973. Archaeological excavations at Sigatoka dune site, Fiji. Suva: Bulletin of the Fiji Museum, No. 1.

Burley, D.V. 1997. Archaeological research Sigatoka sand dune national park. Unpublished report to the Fiji Museum, Suva.

Burley, D.V. 2003. Dynamic landscapes and episodic occupations: Archaeological interpretation and implications in the prehistory of the Sigatoka Sand Dunes. In: Sand, C. (ed), Pacific Archaeology: Assessments and prospects, pp. 307-315. Les Cahiers de l'Archéologie en Nouvelle-Calédonie, Noumea.

Burley, D.V. 2005. Mid-sequence archaeology at the Sigatoka Sand Dunes with interpretive implications for Fijian and oceanic culture history. Asian Perspectives 44: 320-348.

Burley, D.V. and Dickinson, W.R. 2004. Late Lapita occupation and its ceramic assemblage at the Sigatoka Sand Dune site, Fiji and their place in oceanic prehistory. Archaeology in Oceania, 39: 12-25.

Burley, D. and Shortland, R. 1999. Report on 1998 field work activities Sigatoka Dunes National Park Viti Levu, Fiji. Department of Archaeology, Simon Fraser University, Burnaby B.C., Canada.

Crosby, A. 1988. Beqa: Archaeology, structure and history in Fiji. Unpublished MA thesis, Department of Anthropology, University of Auckland.

Crosby, A.D. 1991. Proposal for archaeological survey of Sigatoka Sand Dunes. Unpublished report, Fiji Museum, Suva.

Crosby, A.D. 1992. Further burials at the Sigatoka Sand Dunes Site VL 16/1. Unpublished report, Fiji Museum, Suva.

De Biran, A. 2001. The Holocene geomorphic evolution of the Sigatoka Delta, Viti Levu, Fiji Islands. Unpublished PhD thesis, University of the South Pacific, Suva, Fiji.

Dickinson, W.R. 1968. Sigatoka Sand Dunes, Viti Levu Fiji. Sedimentary Geology 2: 115-124.

Dickinson, W.R., Burley, D.V., Nunn, P.D., Anderson, A., Hope, G., de Biran, A., Burke, C. and Matararaba, S. 1998. Geomorphic and archaeological landscapes of the Sigatoka Dune Site, Viti Levu, Fiji: Interdisciplinary investigations. Asian Perspectives 37: 1-31.

Field, J.S. 2004. Environmental and climatic considerations: a hypothesis for conflict and the emergence of social complexity in Fijian prehistory. Journal of Anthropological Archaeology 23: 79-99.

Frost, E.L. 1979. Fiji. In: Jennings, J.D. (ed), The prehistory of Polynesia, pp. 61-81. Australian National University Press, Canberra.

Gibbons, J. 1985. A brief environmental history of Fiji. II. The Ice Ages and human habitation before European contact. Domodomo 3: 110-123.

Gifford, E.W. 1951. Archaeological excavations in Fiji. University of California Anthropological Records 13: $189-288$.

Gilbert, T. 1984. Limestone and volcanic caves of the Fiji Islands. Transactions of the British Cave Research Association 11: 105-118.

Golson, J. 1974. Both sides of the Wallace Line: New Guinea, Australia, Island Melanesia and Asian prehistory. In: Barnard, N. (ed), Early Chinese art and its possible influence in the Pacific Basin. 
pp. 533-595. Proceedings of a symposium arranged by the Department of Art History and Archaeology, Columbia University, New York City, Taiwan.

Green, R.C. 1963. A suggested revision of the Fiji sequence. Journal of the Polynesian Society 72: 235-253.

Green, R.C. and Palmer, J.B. 1964. Fiji sequence: Corrections and additional notes for Sigatoka. Journal of the Polynesian Society 73: 328-332.

Hudson, E. 1994. Sigatoka Sand Dune site archaeological rescue project 1993. Unpublished report, Auckland Uniservices Limited, Auckland.

Hunt, T.L. 1986. Conceptual and substantive issues in Fijian prehistory. In: Kirch, P.V. (ed), Archaeological approaches to evolution and transformation, pp. 20-32. Cambridge University Press, Cambridge.

Hunt, T.L. 1987. Patterns of human interaction and evolutionary divergence in the Fiji Islands. Journal of the Polynesian Society 96: 299-334.

Kirch, P.V. 1997. The Lapita peoples. Ancestors of the oceanic world. Blackwell Publishers, Cambridge and Oxford.

Kirch, P.V. and Hunt, T.L. (eds) 1997. Historical ecology in the Pacific islands: Prehistoric environmental and landscape change. Yale University Press, New Haven.

Marshall, Y., Crosby, A., Matararaba, S. and Wood, S. 2000. Sigatoka the shifting sands of Fijian prehistory. Oxbow Books, Oxford.

Matthews, P.J. and Gosden, C. 1997. Plant remains from waterlogged sites in the Arawe Islands, west New Britain province, Papua New Guinea: Implications for the history of plant use and domestication. Economic Botany 51: 121-133.

Nunn, P.D. 1990. Coastal geomorphology of Beqa and Yanuca Islands, South Pacific Ocean, and its significance for the tectonic history of the Vatulele-Beqa ridge. Pacific Science 44(4): 348-365.

Palmer, B. 1965. Excavations at Karobo, Viti Levu. New Zealand Archaeological Association Newsletter 8: 26-33.

Palmer, J.B., Shaw, E., Dickinson, P. and Sykes, M. 1968. Pottery making in Sigatoka, Fiji. Records of the Fiji Museum 13.

Parry, J. 1987. The Sigatoka valley - pathways into prehistory. Bulletin of the Fiji Museum No. 9.

Petchey, F. 1994. Pottery and stone analysis. In: Hudson, E. (ed), Sigatoka Dune Site archaeological rescue project 1993, pp. 28-39. Auckland Uniservices Limited, Auckland.

Petchey, F. 1995. Archaeology of Kudon: Archaeological analysis of Lapita ceramics from Mulifanua, Samoa and Sigatoka, Fiji. Unpublished MA thesis, University of Auckland, New Zealand.

Rajotte, F. and Bigay, J. (eds) 1981. Beqa: Island of firewalkers. Institute of Pacific Studies, University of the South Pacific, Suva.

Sawyer, B and Andrews, E.C. 1901. Notes on the caves of Fiji, with special reference to Lau. Proceedings of the Linnean Society of New South Wales 26: 91-106.

Shepherd, M.J. 1990. The evolution of a moderate energy coast in Holocene time, Pacific Harbour, Viti Levu, Fiji. New Zealand Journal of Geology and Geophysics 33: 547-556.

Smith, J.M.B. 1990. Drift disseminules on Fijian beaches. New Zealand Journal of Botany 28: 13-20.

Southern, W. 1986. The late Quaternary environmental history of Fiji. Unpublished PhD thesis, Australian National University, Australia.

Spriggs, M. 1997. The island Melanesians. Blackwell Publishers, Oxford and Massachusetts.

Visser, E.P. 1988. Hotel Masa Survey - Sigatoka. Unpublished report.

Visser, E. 1994. The prehistoric people from Sigatoka: An analysis of skeletal and dental traits as evidence of adaptation. Unpublished PhD thesis, University of Otago, New Zealand.

Whelan, P.W., Gill, J.B., Kollman, R., Duncan, R. and Drake, R. 1985. Radiometric dating of magmatic stages in Fiji. In: Scholl, D.W. and Vallier, T.L. (eds), Geology and offshore resources of Pacific Island arcs - Tonga Region, pp. 415-440. American Association of Petroleum Geologists Special Report 12.

Wood, S., Marshall, Y. and Crosby, A. 1998. Mapping Sigatoka Site VL 16/1: The 1992 field season and its implications. Unpublished report, Fiji Museum, Suva. 